\author{
UNIVERSIDADE DE SÃO PAULO \\ ESCOLA DE ENGENHARIA DE SÃO CARLOS \\ DEPARTAMENTO DE ENGENHARIA DE PRODUÇÃO
}

MARINA CASSIANO RIBEIRO

A Educação como determinante de Complexidade Econômica: um estudo

para Estados-nação 



\title{
A Educação como determinante de Complexidade Econômica: um estudo para Estados-nação
}

\author{
Dissertação apresentada à Escola de \\ Engenharia de São Carlos, Universidade de \\ São Paulo, como parte dos requisitos para a \\ obtenção do Título de Mestre em Engenharia \\ de Produção. \\ Área de concentração: Processos e Gestão de \\ Operações. \\ Orientadora: Prof. Associada Daisy Aparecida \\ do Nascimento Rebelatto \\ VERSÃO CORRIGIDA
}

São Carlos

2019 


\begin{abstract}
AUTORIZO A REPRODUÇÄO TOTAL OU PARCIAL DESTE TRABALHO, POR QUALQUER MEIO CONVENCIONAL OU ELETRÔNICO, PARA FINS DE ESTUDO E PESQUISA, DESDE QUE CITADA A FONTE.
\end{abstract}

Ficha catalográfica elaborada pela Biblioteca Prof. Dr. Sérgio Rodrigues Fontes da EESC/USP com os dados inseridos pelo(a) autor(a).

Cassiano Ribeiro, Marina

C484a A Educação como determinante de Complexidade Econômica: um estudo para Estados-nação. / Marina Cassiano Ribeiro; orientadora Daisy Aparecida do Nascimento Rebelatto. São Carlos, 2019.

- Programa de e Xrea de Concentração em --

Escola de Engenharia de São Carlos da Universidade de Săo Paulo, 2019.

1. Complexidade Econômica. 2. Educação. 3. Análise Envoltária de Dados. 4. Eficiência Social. I. Titulo.

Eduardo Graziosi Silva - CRB - 8/8907 


\section{FOLHA DE JULGAMENTO}

Candidata: Bacharela MARINA CASSIANO RIBEIRO.

Titulo da disssertaçōo: "A educação como determinante de complexidade econômica: um estudo para Estados-naçōot.

Data da defesa: 04/10/2019

Comissōo Julgadora:

Resultado:

Prola. Associada Daisy Aparecida do Nascimento Rebelatto

(Orlentadora)

[Escola de Engenharia de Săo Carlos/EESC]

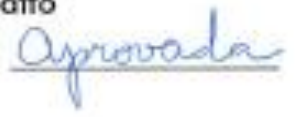

Prof. Dr. Herick Fernando Moralles

(Universidade Federal de São Carios/UFSCar)

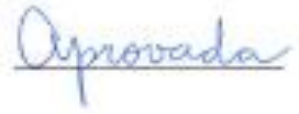

Profa. Dra. Flávia de Castro Camiolo

[Universidade Federal do Triângulo Mineiro/UFTM|

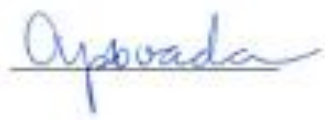

Coordenador do Programa de Pós-Graduaçăo em Engenharia de Produção:

Prof. Dr, Marcelo Seido Nagano

Presidente da Comissão de Pós-Graduoção:

Prof. Titular Murilo Araujo Romero 

Aos meus pais, Eli e Beatriz. 



\section{AGRADECIMENTOS}

Primeiramente, agradeço à Deus por ter me dado forças para concluir esta etapa importante da minha vida.

Agradeço com todo amor e admiração meus pais, Eli e Beatriz, por sempre terem confiando nas minhas escolhas, me incentivarem e darem todo o suporte emocional e financeiro nos meus estudos. Obrigada por fixarem na minha mente que a educação é transformadora e libertadora.

Agradeço ao meu marido João Paulo por ser meu porto seguro e me incentivar em todas as minhas escolhas. Sou grata por ser muito mais do que meu esposo, mas também amigo, companheiro e incentivador. Obrigada por estar sempre ao meu lado nos momentos de alegria e dificuldades.

Sou grata à Prof. Daisy A. do Nascimento Rebelatto pela orientação, incentivo à pesquisa e, especialmente, por ter confiado em mim como aluna de mestrado. Obrigada por sua solicitude e disposição em debater e me auxiliar neste trabalho.

Agradeço aos professores Herick Fernando Moralles e Flavia Camioto pelos comentários relevantes no exame de qualificação.

Agradeço aos meus amigos queridos do Laboratório de Administração e Economia, Mirian Wawrzyniak Chimirri e Diogo Ferraz por todo o apoio e ajuda durante o meu mestrado. Este trabalho não seria concluído ou possível sem o auxílio de vocês.

Deixo meu agradecimento a todos os funcionários do departamento de Engenharia de Produção da Escola de Engenharia de São Carlos - USP. 



\section{RESUMO}

\section{RIBEIRO, Marina Cassiano. A Educação como determinante de Complexidade Econômica:}

um estudo para Estados-nação. 2019. Dissertação (Mestrado) - Escola de Engenharia de São Carlos. Universidade de São Paulo, São Carlos, 2019.

Existem críticas sobre o uso do crescimento econômico como um indicador satisfatório para o desenvolvimento humano. Neste sentido, verifica-se a necessidade de formular novos indicadores que atendam tais anseios. O objetivo do presente trabalho é mensurar a eficiência dos Estados-nação em converter indicadores educacionais em complexidade econômica. Para isto, a relação entre educação e complexidade econômica será analisada por meio de modelos econométricos a fim de validar os inputs e outputs do modelo de eficiência, além de mensurar a forma como o fenômeno se relaciona. Comprova-se que existe forte correlação entre os indicadores educacionais utilizados e complexidade econômica. Após a análise das variáveis, foi mensurada a eficiência dos Estados-nação por meio do método Análise Envoltório de Dados (DEA) e a respectiva classificação dos países mais eficientes para os menos eficientes. O ranking mostrou que o país mais eficiente foi a Eslováquia, seguida pelo Japão e México. Tal resultado mostra que a maioria dos países eficientes não são, necessariamente, os com índices educacionais mais elevados, mas sim, os que dado o nível educacional conseguem gerar maior nível de complexidade econômica.

Palavras-chave: Complexidade Econômica; Educação; Análise Envoltória de Dados (DEA); Eficiência Social. 



\begin{abstract}
RIBEIRO, Marina Cassiano. Education as a determinant of Economic Complexity: a study for Nation-states. 2019. Dissertation (Master's) - Escola de Engenharia de São Carlos. Universidade de São Paulo, São Carlos, 2019.

There are criticisms of the use of economic growth as a satisfactory indicator for human development. It is argued that wealth does not necessarily produce quality of life or benefit social indicators, such as educational indicators. In this sense, there is a need to formulate new indicators that meet these needs. The purpose of this paper is to measure the efficiency of nation-states in converting educational indicators into economic complexity. For this, the relationship between education and economic complexity will be analyzed through econometric models in order to validate the inputs and outputs of the efficiency model, in addition to measuring the way the phenomenon relates. It is verified that there is a strong correlation between economic complexity and educational indicators analyzed. After analyzing the variables, the efficiency of the nation-states was measured using the Data Envelopment Analysis (DEA) method and the respective classification of the most efficient countries for the least efficient. The ranking showed that the most efficient country was Slovakia, followed by Japan and Mexico. This result shows that most efficient countries are not necessarily those with the highest educational levels, but those that, given the educational level, can generate the highest level of economic complexity.
\end{abstract}

Keywords: Economic Complexity; Education; Data Envelopment Analysis (DEA); Social Efficiency. 



\section{LISTA DE FIGURAS}

Figura 1 - Concepção de um país como um sistema produtivo ............................................ 29

Figura 2 - Fluxograma e hipótese do fenômeno analisado....................................................56 



\section{LISTA DE GRÁFICOS}

Gráfico 1 - Evolução da eficiência dos países selecionados entre 2007 e 2016 ............76 



\section{LISTA DE TABELAS}

Tabela 1- Estatísticas descritivas das variáveis do modelo 59

Tabela 2 - Matriz de Correlação entre os inputs e outputs 63

Tabela 3- Estimativas econométricas para os países da amostra. 65

Tabela 4- Eficiência dos países entre 2001 a 2015 67

Tabela 5 - Eficiência dos países nos anos 2007, 2011 e 2016 .76 



\section{LISTA DE QUADROS}

Quadro 1 - Base de dados coletada e em análise no trabalho............................................. 53

Quadro 2 - Principais modelos radiais DEA na forma de multiplicadores 555 



\section{SUMÁRIO}

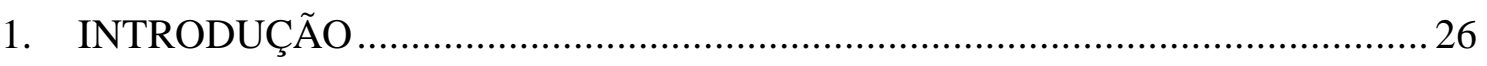

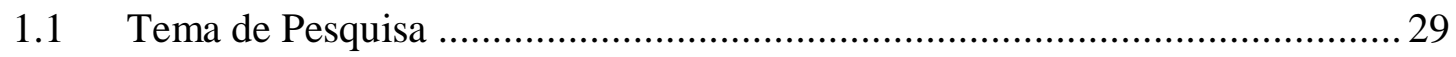

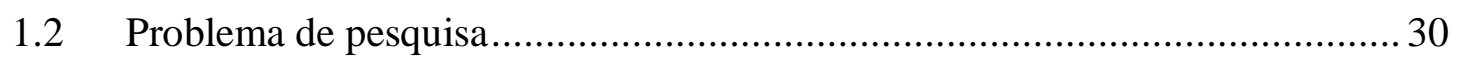

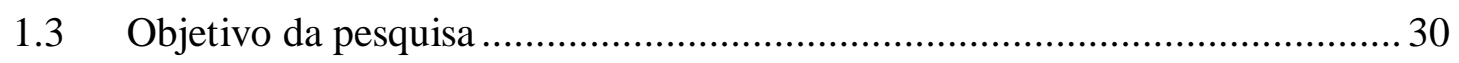

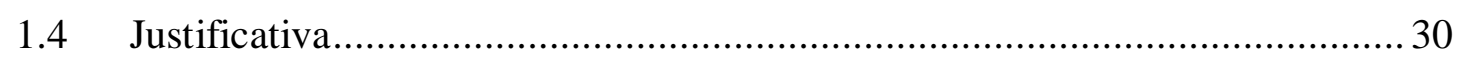

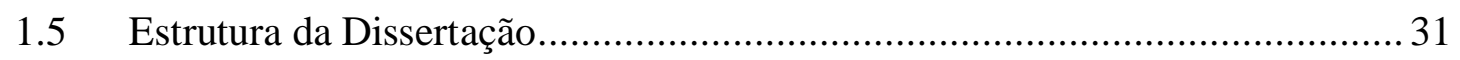

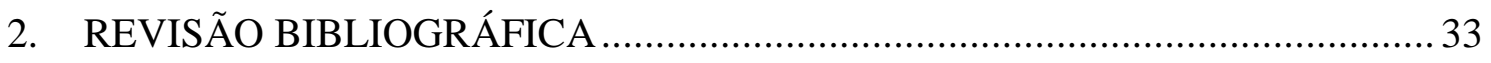

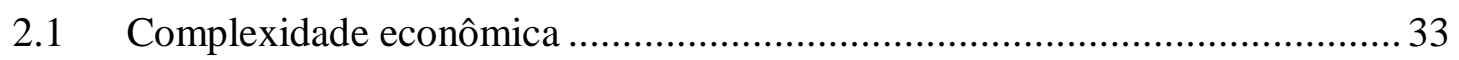

2.2 Educação, desenvolvimento econômico e humano ....................................... 35

2.3 A evolução da educação no Brasil .............................................................. 41

2.4 Educação, inovação e complexidade: uma nova perspectiva de análise..........47

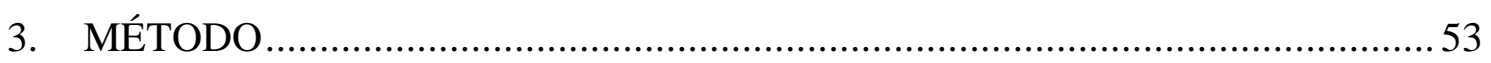

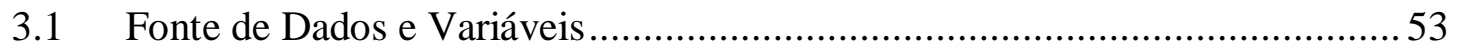

3.2 Análise Envoltória de Dados - DEA .......................................................... 54

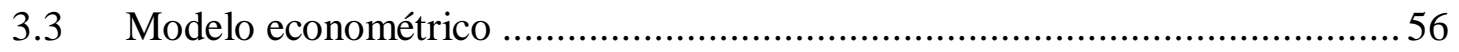

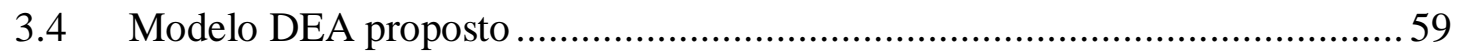

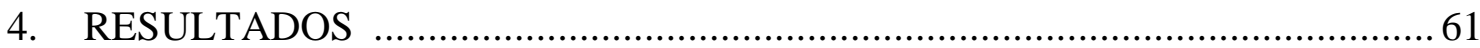

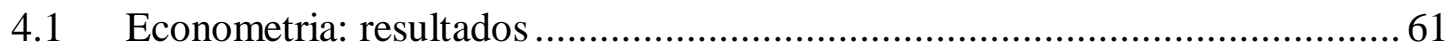

4.2 Análise da eficiência entre os anos de 2007 a 2016 ..................................... 66

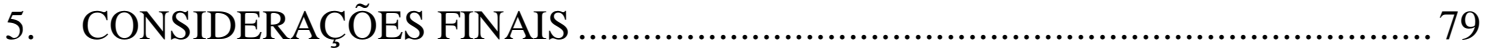

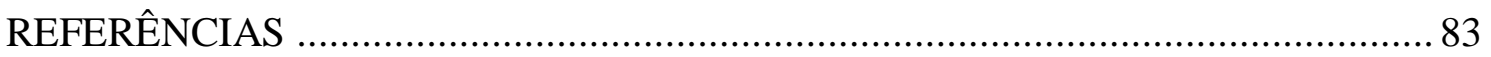





\section{INTRODUÇÃO}

Economistas têm se concentrado em analisar o papel do capital natural, físico e humano como determinantes fundamentais do crescimento econômico (SOLOW, 1956; GROSSMAN, HELPMAN, 1991; STOKEY, 1988, 1991; YOUNG, 1991; LUCAS, 1988, 1993). Os modelos econômicos encontrados na literatura têm início com uma base macroeconômica e mostram que o progresso tecnológico determina o crescimento de longo prazo, por exemplo, o Modelo de Solow (SOLOW, 1956).

O modelo de Solow (1956) é o mais conhecido dentro desta abordagem. Este modelo avalia o crescimento da economia de um país a longo prazo. O crescimento econômico depende da acumulação de capital, do crescimento da força de trabalho e das alterações tecnológicas. Além disso, o modelo avalia o papel da poupança como principal determinante do estoque de capital no equilíbrio.

A partir do final da década de 1980, uma série de modelos de crescimento que levam em conta o surgimento de novos bens e serviços e o caráter endógeno da mudança tecnológica foi desenvolvida. Tais modelos se concentram na acumulação do conhecimento, seja em livros e empresas como tecnologia ou em pessoas como capital humano. Como por exemplo, os modelos de Romer (1987, 1990), Aghion e Howitt (1998), Grossman e Helpman (1991) e Lucas (1988, 1993).

Estudos mais recentes abordam que não é o crescimento econômico em si, mas sim a qualidade deste crescimento que determina o bem-estar da população (LOPES et al., 2008; MARIANO E REBELATTO, 2013). Em suma, o crescimento econômico é uma condição necessária, mas não suficiente, para que todos possam alcançar condições de vida mais completas e mais felizes (RANIS et al., 2000; KLIKSBERG, 2001). Assim, o bem-estar social de um país não está relacionado apenas com o crescimento econômico, mas também com fatores como educação, nível de produtividade dos trabalhadores e tecnologia empregada no país.

Economistas e outros pesquisadores têm acumulado uma quantidade de evidências de que a educação aumenta a produtividade dos trabalhadores, o que eleva os rendimentos. Há também evidências de que a educação aumenta a taxa de crescimento econômico. Além disso, uma sociedade mais educada se torna mais eficaz na introdução de novas tecnologias, tornando os países mais diversificados e competitivos (HANUSHEK E WOESSMANN, 2008). Essas externalidades fornecem motivos adicionais para uma atenção especial com a educação e diversificação econômica nos países. 
A inovação é concentrada espacialmente e está fortemente relacionada ao papel das externalidades do conhecimento, assim como com a concentração geográfica da produção (AUDRETSCH e FELDMAN, 1996). Dois tipos de externalidades geográficas, identificadas na literatura, com um papel importante na criação e difusão do conhecimento foram a especialização e a diversidade (BEAUDRY e SCHIFFAUEROVA, 2009; GLAESER et al., 1992).

GLAESER et al. (1992) formalizaram o trabalho de MARSHALL (1890), ARROW (1962) e ROMER (1986) e propuseram o conceito das externalidades Marshall-Arrow-Romer (MAR), em que a aglomeração de uma indústria a nível regional facilita os spillovers de conhecimento entre empresas e melhora a capacidade inovadora do setor (BEAUDRY e SCHIFFAUEROVA, 2009). Primeiramente, o conhecimento pode ser compartilhado com custos de transmissão mais baixos dentro do mesmo setor (SAXENIAN e HSU, 2001). Segundo, a proximidade facilita a transferência de conhecimento (EDLER et al., 2011), atividades colaborativas de P\&D e comunicações. Terceiro, a localização industrial às vezes prefere um ambiente menos competitivo (GLAESER et al., 1992), no qual se concentram recursos valiosos de P\&D.

Por outro lado, JACOBS (1969) argumenta que a diversidade é a principal fonte para inovação, porque quanto maior o número e a variedade da divisão do trabalho, maior a capacidade da economia para gerar mais tipos de bens e serviços. Pesquisadores que apoiam os modelos de Jacobs afirmam que as fontes mais importantes de externalidades de conhecimento são externas à indústria em que a empresa opera (BEAUDRY e SCHIFFAUEROVA, 2009). O efeito interativo da comunicação entre diferentes indústrias, especialmente os setores complementares, é considerado uma forma crucial de recombinação e recreação do conhecimento (GLAESER et al., 1992). Acredita-se que maiores oportunidades de imitar, compartilhar e recombinar ideias e práticas em todos os setores estejam inseridas em uma economia regional mais diversificada (BEAUDRY e SCHIFFAUEROVA, 2009).

Uma análise utilizada para avaliar a importância da diversificação e especialização econômica é por meio do conceito de Complexidade Econômica. Para Hausmann et al. (2014, p. 18), a complexidade de um país decorre do tipo de bens produzidos, o que se reflete sobre sua estrutura produtiva. Países mais complexos produzem bens com alto valor agregado, portanto diferenciados. A introdução do conceito de complexidade econômica expandiu a capacidade de quantificar a estrutura produtiva dos países (HAUSMANN, HWANG, RODRIK, 2007; HIDALGO et al., 2007; HIDALGO, HAUSMANN, 2009; FELIPE et al., 2012).

Hidalgo e Hausmann (2009) comprovaram que a diversificação econômica, em direção a setores intensivos em tecnologia, conduz um país ao crescimento econômico e à elevação da 
renda no longo prazo. Hartmann (2014) também mostrou que a diversificação econômica é mais importante para o desenvolvimento humano do que o crescimento econômico, pois a complexidade melhora a capacidade das pessoas, ao gerar melhor nível educacional, saúde e indicadores de infraestrutura. Uma economia fortemente avançada tecnologicamente exige uma mão de obra com qualidade técnica e educacional igualmente desenvolvida. Logo, espera-se que haja forte correlação entre a complexidade econômica e os indicadores educacionais.

Neste trabalho entende-se educação como um indicador qualitativo, uma vez que a complexidade econômica tende a exigir pessoas capacitadas em tecnologia e conhecimento técnico, contribuindo para o desenvolvimento social e econômico.

Com base na importância do nível de diversificação dos países, ou seja, no grau de complexidade dos Estados-nação, assim como a relevância dos indicadores educacionais e do nível tecnológico para o crescimento econômico e bem-estar da população, o presente trabalho tem foco na relação entre educação e complexidade econômica das nações, no intuito de averiguar quais são as melhores práticas utilizadas pelos países.

\subsection{Tema de Pesquisa}

O tema abordado no presente trabalho é a relação entre indicadores educacionais e complexidade econômica. Como tal relação é complexa e multidimensional, utilizam-se técnicas econométricas e cálculo da eficiência por meio do Data Envelopment Analysis (DEA). Desta forma, neste trabalho os países foram analisados como se fossem sistemas produtivos, cujo objetivo é transformar educação (inputs) em complexidade econômica (outputs).

Figura 1 - Concepção de um país como um sistema produtivo

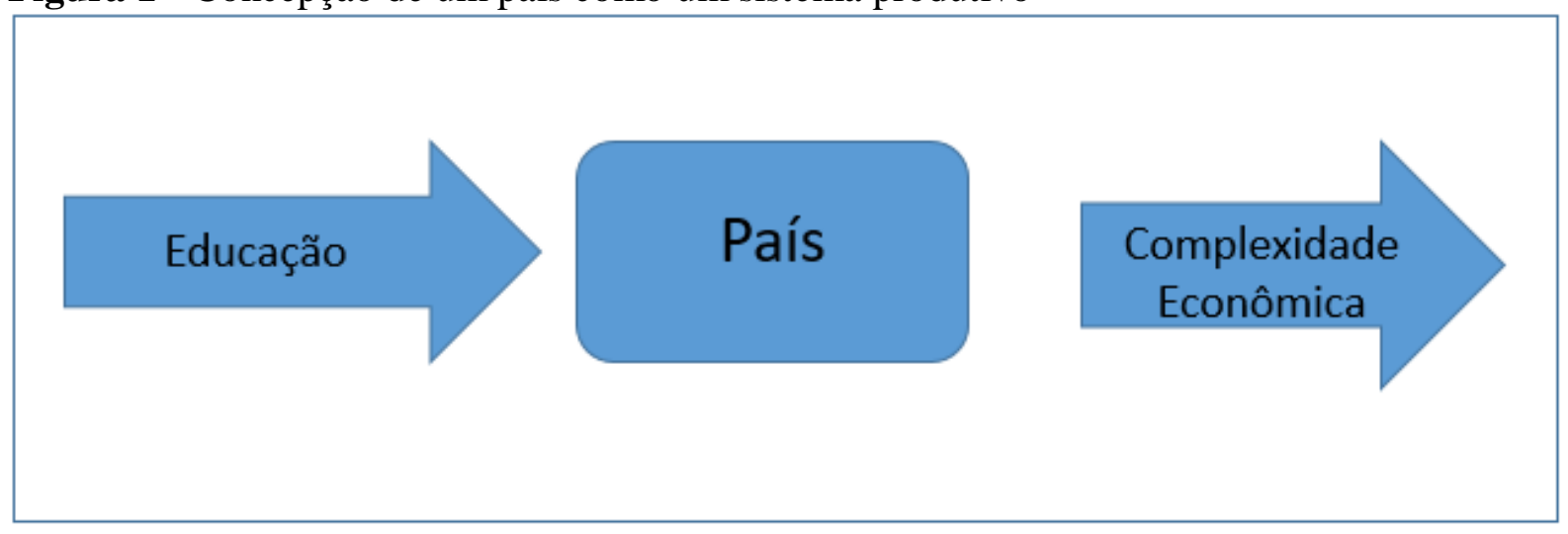

Fonte: Adaptado de Mariano (2012)

Considera-se também que o processo de desenvolvimento possui diferentes estágios. No primeiro estágio, a educação se transforma em riqueza. No segundo estágio, a riqueza se 
transforma em complexidade econômica. No terceiro estágio, a educação se transforma em complexidade econômica. Neste último, foco deste trabalho, a transmissão da educação para geração de complexidade econômica pode-se dar através de investimentos diretos na educação, demanda dos países mais competitivos (complexos) por mão de obra especializada ou pela necessidade dos países de terem vantagem comparativa em produtos de alto valor agregado e, consequentemente pessoas capacitadas para geração dessa competitividade. Logo, o estudo focará na complexidade econômica como função dos indicadores educacionais.

\subsection{Problema de pesquisa}

O problema desta dissertação pode ser descrito por meio da seguinte pergunta de pesquisa: quais as melhores práticas no mundo, ou seja, quais os países mais eficientes em converter indicadores educacionais em complexidade econômica? Essa questão pode ser decomposta em outras perguntas secundárias, tais como:

1. É possível verificar se a educação tem influência sobre a complexidade econômica?

2. Quais países são mais eficientes em converter educação em complexidade econômica?

\subsection{Objetivo da pesquisa}

O presente trabalho tem como objetivo geral mensurar a eficiência dos Estados-nação em converter indicadores educacionais em complexidade econômica. A fim de uma melhor compreensão, tal objetivo ramifica-se em objetivos secundários, a saber:

1. Revisão da literatura sobre complexidade econômica e educação, assim como a relação existente entre essas variáveis;

2. Definir os inputs para educação e o output para a complexidade econômica no modelo de eficiência;

3. Estimação econométrica a fim de validar os inputs e outputs utilizados na pesquisa;

4. Estimar o modelo DEA e mensurar a eficiência dos países em transformar indicadores educacionais em complexidade econômica;

5. Analisar e comparar os resultados do ranking de eficiência gerado para os países analisados neste trabalho.

\subsection{Justificativa}


A principal justificativa para a realização desta dissertação é o hiato de trabalhos científicos abrangendo o tema abordado deste trabalho. Existem diversos estudos que abordam a relação entre complexidade e crescimento econômico (FELIPE, KUMAR, ABDON, BACATE, 2012; HAUSMANN, HWANG, RODRIK, 2007; FERRARINI, SCARAMOZZINO, 2016). Entretanto, existe uma lacuna de trabalhos que criem indicadores de eficiência mensurando o processo de transformação de educação em complexidade econômica.

Analisar a influência da educação sobre a complexidade econômica é um tema relevante, pois países mais complexos possuem mais condições e necessidade de investimento em mão de obra especializada, ou seja, educação, assim como em P\&D e tecnologia, uma vez que a geração de produtos complexos exige um alto grau de diferenciação, inovação e conhecimento. Logo, educação gera mais complexidade econômica em um país, que por sua vez demanda mais educação, gerando um círculo virtuoso. Dessa forma, definir quais são os países mais eficientes na transformação de indicadores educacionais em complexidade econômica é importante para identificar exemplos de países desenvolvidos economicamente e socialmente.

Mais importante, este tipo de análise auxilia países emergentes, como o Brasil, a compreender as políticas educacionais desenvolvidas pelos países que estão na fronteira tecnológica das melhores práticas mundiais. Evidentemente, não se espera que as políticas educacionais sejam simplesmente copiadas de um país para o outro, pois a estratégia de políticas públicas precisa levar em consideração as questões culturais e a diversidade social e econômica entre os países e, até mesmo, a heterogeneidade dentro do território de cada nação.

Além disso, argumenta-se que existem trabalhos que abordam a relação entre complexidade econômica, crescimento econômico e desenvolvimento humano que utilizam o método de Análise Envoltória de Dados (DEA) (FERRAZ et al., 2018). Entretanto, não foram encontrados estudos que abordassem a relação exclusiva entre a complexidade econômica e a educação, em especial, utilizando métodos econométricos a fim de validar as variáveis utilizadas, bem como DEA para calcular a eficiência deste processo.

\subsection{Estrutura da Dissertação}

Além deste capítulo introdutório, o presente trabalho apresenta mais três capítulos. $\mathrm{O}$ Capítulo 2 contém a revisão bibliográfica sobre o tema do trabalho. O capítulo inicia-se com conceitos e teorias sobre complexidade econômica, educação formal e capital humano e P\&D e inovação. 
O capítulo 3 apresenta o método utilizado nesta pesquisa que abrange a base de dados, os modelos econométricos e, em seguida, discute-se sobre o modelo DEA a ser utilizado neste trabalho.

O capítulo 4 traz os resultados das estimativas da análise econométrica para os países, a classificação dos países eficientes em converter complexidade econômica em indicadores educacionais, assim como uma discussão sobre os modelos educacionais adotados em alguns países que obtiveram uma boa colocação no ranking de eficiência.

Por fim, o capítulo 5 traz considerações finais e os próximos passos para continuidade desta linha de investigação. 


\section{REVISÃO BIBLIOGRÁFICA}

Este capítulo apresenta a revisão bibliográfica sobre os principais temas considerados neste trabalho, no intuito de dar embasamento teórico para a escolha das variáveis e dos modelos de eficiência, bem como auxiliar nos resultados encontrados.

\subsection{Complexidade econômica}

Esta seção discute trabalhos encontrados na literatura econômica sobre a importância da complexidade para o crescimento econômico e o desenvolvimento humano em diversos países. Além disso, será dada atenção para estudos que tenham associado a influência de indicadores educacionais e da inovação sobre a complexidade econômica.

A capacidade de um país para desenvolver e expandir um conjunto de estruturas de produção complexas exige a disponibilidade de um conjunto de habilidades abrangentes ou capacidades que sejam adaptáveis à mudança de tecnologia (FERRARINI E SCARAMOZZINO, 2016, p. 52).

Lewis (1955), Rostow (1959) e Kaldor (1967) retrataram o desenvolvimento econômico essencialmente como um processo de transformação estrutural e aumento da produtividade, impulsionado pelo fortalecimento progressivo das capacidades produtivas, bem como pela realocação de recursos.

Posteriormente, Lall (1992) e Kremer (1993) ligaram as capacidades ao crescimento econômico e ao desenvolvimento por meio do seu impacto sobre a inovação. Sutton (2001) mostrou que a capacidade das economias modernas em explorar capacidades escassas é a raiz do sucesso dos países desenvolvidos.

Na Teoria das Capacidades Ocultas de Hidalgo e Hausmann (2009), capacidades se referem a recursos fundamentais especiais que representam todos os recursos da economia do país e as características da organização social nacional possibilitando a produção e a exportação da cesta de bens comercializáveis pelo mesmo país.

As capacidades são todos os ativos intangíveis que impulsionam o desenvolvimento, a riqueza e a competitividade dentro do território nacional. Quando a estrutura de produção de um país é mais complexa, as capacidades de produção são mais fortes. Um país com maiores capacidades poderá participar de atividades de produção social com maior produtividade, e assim, o país se desenvolverá mais rápido (FELIPE et al., 2012). Logo, para estes autores, desenvolvimento econômico não é apenas um processo de melhoria contínua na produção de um mesmo conjunto de bens, mas sim um processo que exige a aquisição de um conjunto de 
capacidades mais complexa para o desenvolvimento de atividades com maiores níveis de produtividade e, consequentemente mais tecnologia.

Hidalgo et al. (2007) e Hidalgo e Hausmann (2009) por meio do Método da Teoria em Rede mostraram que o caminho para o desenvolvimento de um país é determinado por sua capacidade de acumular as capacidades que são exigidas para a produção de bens mais variados e, especificamente mais sofisticados. Logo, a complexidade da estrutura produtiva de um país é a variável chave para explicar desenvolvimento e crescimento econômico.

Para Hausmann et al. (2014), a complexidade econômica define a estrutura produtiva de uma nação. A capacidade de produzir maquinários, equipamentos médicos e outros produtos de alta tecnologia, torna os países mais complexos do que aqueles que exportam apenas commodities. Nações com baixa diversificação são capazes de exportar menos produtos e com menor intensidade tecnológica (TACCHELLA et al., 2013; GALA, 2017). Portanto, países mais complexos exportam produtos com um valor agregado mais elevado, em função da alta tecnologia empregada, e são mais produtivos do que países menos complexos.

Outra forma de interpretar a complexidade econômica de um país é compreender que os tipos de produtos desenvolvidos decorrem de uma multiplicidade de conhecimento disponível. Em uma economia complexa, indivíduos em uma variedade de empregos (finanças, marketing, tecnologia, recursos humanos, operações, leis) precisam interagir e combinar seus conhecimentos para fazer produtos sofisticados. Sem esse conhecimento disponível, os países não conseguem produzir produtos e riqueza (HAUSMANN et al., 2014). Ou seja, é necessário que exista uma rede de conhecimentos e habilidades (educação) bem integrada para que um país seja desenvolvido economicamente e socialmente.

Hidalgo e Hausmann (2009) definem a complexidade do espaço de produto como uma medida de diversificação e ubiquidade. A diversificação é o número de produtos que um país exporta com vantagem comparativa revelada (RCA). Ubiquidade é o número de países que exportam um produto com RCA. Um país que exporta mais bens com RCA, ou seja, é mais diversificado, é mais complexo do que um país que exporta menos bens com RCA. Um produto que é exportado por menos países com RCA, ou seja, é menos onipresente, é mais complexo do que um produto que é exportado com RCA por mais países. A conclusão é que um país pode exportar um produto específico com vantagem comparativa revelada se possuir as capacidades necessárias e específicas. Por exemplo, habilidades trabalhistas, instituições, máquinas, insumos públicos, insumos negociáveis, etc. Assim, um país mais diversificado possui mais capacidades. Do mesmo modo, um produto que é menos onipresente requer capacidades mais exclusivas. A complexidade, portanto, está associada ao conjunto de capacidades exigidas por 
um produto (complexidade do produto) ou com o conjunto de capacidades disponíveis em uma economia (complexidade econômica).

Uma forma de mensurar o grau de complexidade econômica de um país é através do Índice de Complexidade Econômica (ECI). Tal índice mede a sofisticação da estrutura produtiva de um país ao combinar informações sobre a diversidade de produtos exportados por um país e o número de países que exportam esses produtos. A ECI é calculada a partir de dados exportados que conectam os países aos produtos em que possuem vantagens comparativas reveladas (HIDALGO E HAUSMANN, 2009). Quanto maior o ECI, mais diversificadas são as exportações e mais complexa será a economia.

Trabalhos recentes sobre estruturas produtivas destacou que a complexidade e a diversidade de produtos exportados pelo país são uma boa proxy para o conhecimento e know-how disponível em uma economia que não é capturada por medidas agregadas do capital humano, por exemplo, os anos de escolaridade ou a percentagem da população com ensino superior (HIDALGO, 2015).

Dois fatores que influenciam o aumento do Índice de Complexidade Econômica de um país são a diversificação da exportação, que é a habilidade de exportar produtos de alta tecnologia e o gasto com Pesquisa e Desenvolvimento (P\&D). Gastos com P\&D são importantes, pois diversificação e exportação de produtos de alta tecnologia exigem inovação. São as atividades de pesquisa que providenciam conhecimento necessário para a criação de inovações (SAVIOTTI E PYKA, 2013).

Segundo Saviotti et al. (2016), a mudança estrutural causada pela inovação é a principal forma de criar novos setores que são fundamentais para a sustentação do desenvolvimento econômico. Desta forma, os gastos em educação, especialmente em Pesquisa e Desenvolvimento (P\&D) são importantes, uma vez que, para que ocorra a diversificação de produtos nos países é necessário inovar. A próxima seção analisa a relação entre educação formal, capital humano e desenvolvimento econômico.

\subsection{Educação, desenvolvimento econômico e humano}

O papel do capital humano na promoção do desenvolvimento econômico é bem reconhecido na literatura de crescimento. Como a produção de bens requer as interações de diferentes capacidades que também são afetadas pelo nível de capital humano, presume-se que este deve ser um fator importante que interage com a complexidade econômica.

Wang et al. (2010) e Zhu e Fu (2013) observam que o capital humano é um fator importante que afeta a complexidade das exportações. Além disso, Hausmann et al. (2014) descobriram 
que existe uma relação positiva entre complexidade e capital humano. A produção de bens requer não apenas capacidades diferentes, mas também suas interações. Essas interações dependem de diferentes insumos trabalhistas. Portanto, a acumulação de capital humano fornece o pré-requisito para cultivar e utilizar plenamente as capacidades de produção.

Segundo Costinot (2009), o aperfeiçoamento da qualidade do capital humano pode fazer com que um país desenvolva uma vantagem comparativa na produção de bens mais complexos. Portanto, o aperfeiçoamento do capital humano pode promover um avanço das capacidades dos produtos nacionais.

Muitas pesquisas, por outro lado, se concentraram no impacto da educação formal sobre o crescimento econômico. Entre esses estudos, Levine e Renelt (1992), Mankiw et al. (1992), Barro e Sala-i-Martin (1997), Barro (1997) encontraram uma relação positiva entre taxa de matrícula e/ou escolaridade e crescimento. Segundo Mankiw et al. (1992), países que cresceram acima da média no período de 1960 a 1989 tenderam a ter uma maior participação das exportações no PIB, maior participação de investimento no PIB, maiores taxas de matrícula no ensino fundamental e médio e taxas de inflação mais baixas do que os países de crescimento mais lento.

Os modelos teóricos de crescimento econômico enfatizaram diferentes mecanismos por meio dos quais a educação pode afetar o crescimento econômico, destacando, respectivamente, o papel da educação como fator de produção que pode ser acumulado (MANKIW et al., 1992), seu papel no aumento da capacidade inovadora da economia (AGHION E HOWITT, 1998; ROMER, 1990), ou sua função como facilitadora da transmissão do conhecimento necessário para implementar novas tecnologias (BENHABIB E SPIEGEL, 2005). O que todas essas abordagens têm em comum é que eles predizem que a educação tem um efeito positivo sobre o crescimento.

Bourguignon-Verdier (2000) sugerem que a participação política de pessoas de baixa renda aumenta com seu nível educacional e que, consequentemente, as políticas redistributivas surgem com o desenvolvimento educacional. Morrisson-Murtin (2008) utilizaram dados globais de Bourguignon-Morrisson (2002) sobre a distribuição de renda e descobriram que a educação em massa desencadeou um declínio dramático na desigualdade a partir de 1870, além de quaisquer variações ligadas ao PIB per capita ou ao capital humano.

Segundo Breton (2013) a educação tem efeitos diretos e indiretos na produção nacional. Trabalhadores educados aumentam a renda nacional diretamente porque a escolaridade aumenta sua produtividade marginal. Eles também aumentam indiretamente a renda nacional ao elevar a produtividade marginal do capital físico e de outros trabalhadores. Uma das 
evidências encontradas pelo autor é que em países altamente educados, o efeito spillover sobre outros trabalhadores é mínimo, mas em países menos educados tal efeito parece ser muito maior. Outro resultado dos efeitos da educação sobre a economia foi que o retorno marginal do investimento em educação é muito grande em países com populações com baixa escolaridade, mas é muito menor em países com populações altamente educadas. Todos os países com altos níveis de capital humano oferecem educação pública gratuita ou obrigatória ou fundos públicos para ensino privado através do nível secundário. A evidência histórica indica que, se os países pobres desejam crescer, eles devem fornecer esse apoio financeiro para a educação primária e secundária (BRETON, 2013).

Alguns autores como Jamison e Hanushek (2007), Hanushek (2006), Hanushek e Kimko (2000) e Hanushek e Woessmann (2008) abordam a educação como habilidades cognitivas desenvolvidas pelo indivíduo e não como educação formal. Eles concordam que é a qualidade escolar de uma nação, medida por pontuações em testes internacionais de habilidades de matemática e ciências, em vez da quantidade de escolaridade, medida por anos médios de estudo que está associada à economia crescimento. Com base nisto, foi utilizado neste trabalho proxies de qualidade da educação e qualidade em matemática e ciências.

Breton (2013) também examinou o papel da educação no crescimento econômico a partir de uma perspectiva teórica e histórica. Segundo o autor, o primeiro compromisso nacional com a escolarização das massas aparentemente ocorreu após a Reforma Protestante no século XVI. Os líderes de várias seitas protestantes no norte da Europa promoveram a alfabetização para que seus membros pudessem ler a Bíblia e estudar o catecismo religioso. Esta obrigação religiosa foi a base para os primeiros esforços significativos para criar escolas para a população de baixa renda.

Diversas pesquisas documentam o aumento da alfabetização que ocorreu após a Reforma Protestante do Cristianismo (CIPOLLA, 1969). A competição entre grupos religiosos protestantes e católicos para atrair fiéis estimulou ainda mais a oferta de educação gratuita ou subsidiada para os pobres em regiões onde ambos os grupos estavam ativos. Em 1700, 35 a $40 \%$ da população na Europa protestante conseguia ler, enquanto na Europa católica do sul menos de 20\% eram alfabetizados (JOHANSSON, 1977).

A oposição da Igreja Católica à educação desacelerou o fornecimento de educação para as pessoas no sul da Europa católica e nas colônias ibéricas. À medida que os níveis nacionais de educação aumentaram de 1850 para 1940, a Europa Protestante do Norte manteve sua vantagem histórica em relação à Europa Católica do Sul, com diferenças particularmente grandes em 
relação à Espanha e Portugal (BENAVOT E RIDDLE, 1988). Em 1940, os índices de matrícula da escola primária eram cerca de $70 \%$ no norte da Europa e seus assentamentos, $60 \%$ na Itália e $35 \%$ na Ibéria e seus assentamentos.

O Japão é a principal exceção, uma vez que adotou conscientemente as práticas de escolaridade europeias como parte de sua estratégia nacional de desenvolvimento. Em 1870, o Japão alcançou níveis de matrícula primária comparáveis aos do sul da Europa (BENAVOT E RIDDLE, 1988). O Japão e a Coréia do Sul são exemplos de países que desenvolveram forte capacidade tecnológica em suas grandes empresas privada antes de desenvolver suas universidades de pesquisa, mas, mais recentemente, começaram a sentir a necessidade de promover suas melhores universidades aos padrões das americanas e europeias (ALTBACH E BALÁN 2007; INDIRESAN 2007; KIM E NAM, 2007; LIU 2007; YONEZAWA 2003).

No que diz respeito à acumulação de capital humano, o desempenho da Coreia do Sul tem sido notável. O número de anos médios de escolaridade aumentou de apenas 4,1 anos em 1960 para 12,0 anos em 2010. Como resultado, a diferença no nível educacional médio entre a Coreia e os EUA diminuiu substancialmente. Houve um rápido aumento das taxas de matrícula escolar para todos os níveis de educação. Considerando que as taxas de matrícula nos níveis secundário e terciário não aumentarão muito além dos níveis atuais, que estão entre os mais altos do mundo, a velocidade do acúmulo de capital humano na Coreia acabará desacelerando (LEE, 2016, p. $81)$.

Morrisson e Murtin (2008) construíram uma série consistente da escolaridade média de 74 países para o período 1870-2010. Tais autores fizeram uma sólida revisão sobre a evolução da educação em diversos países.

A educação tem uma longa história na Alemanha, cujo início retorna a Frederico o Grande, que exigiu a frequência escolar entre 5 e 13 anos em 1763. Como resultado, a Prússia e a Alemanha, como um todo, alcançaram altos níveis de matrícula no início do século XIX, igualados apenas por Noruega em 1830. Em 1920, a frequência escolar tornou-se obrigatória até 18 anos. As principais reformas do sistema educacional ocorreram na década de 1970 (MORRISON E MURTIN, 2008). Segundo o relatório da Organisation for Economic for Cooperation and Development (OECD), publicado em 2017, a expansão educacional alemã pode ser caracterizada por uma alta estabilidade global ao longo do tempo, que reflete sua longa tradição de educação e treinamento vocacional. Ao longo das gerações, mais de metade dos jovens adultos iniciaram um programa de aprendizagem e obtiveram uma qualificação de ensino secundário ou pós-secundário não superior amplamente reconhecida pelos empregadores. 
No Reino Unido, a rainha Victoria eliminou a prática do trabalho infantil em 1833 e introduziu a escolaridade obrigatória no ensino fundamental de 1870. A mesma competição entre o Estado e a Igreja pelo monopólio da educação pública prevaleceu na maioria dos países anglo-saxões e na França. Além disso, muitas vezes é enfatizado que os capitalistas industriais pressionaram o governo para promover a educação em massa, que era complementar à rápida mudança tecnológica da industrialização. No período pós-guerra, o ensino médio e a educação universitária explodiram após 1970 (MORRISON E MURTIN, 2008).

Na Argentina, o nível de educação média era de 2 anos em 1870 e cresceu muito devagar ao longo dos anos. Em 1874, foram implementadas reformas que implementaram 8 anos de escolaridade gratuita e obrigatória, mas o nível correspondente de escolaridade média na população não foi alcançado até a década de 1950 (MORRISON E MURTIN, 2008).

Para os Estados Unidos, no início do século XIX, surgiu a ideia de uma escola pública gratuita, defendida por visionários como Thomas Jefferson. No entanto, o estado federal não desempenhou um papel importante no processo educacional, exceto pela fundação de academias militares. $\mathrm{O}$ alto nível de alfabetização alcançado na véspera do século XX foi rapidamente seguido pelo "movimento da escola secundária" que acelerou na década de 1920. A década de 1950 marcou o fim da segregação nas escolas. Então, na Lei de Ensino Fundamental e Secundário de 1965, a ajuda federal aumentou e a taxa de graduação do ensino médio atingiu cerca de 80\% em 1970 (Departamento de Educação dos EUA (1993)). Em geral, o crescimento da educação tem sido notavelmente constante ao longo de todo o período (MORRISON E MURTIN, 2008).

Os países da Organização para a Cooperação e Desenvolvimento Econômico (OECD) seguiram caminhos e dinâmicas diferentes em sua expansão educacional. Em todos os países, o nível de escolaridade dos jovens adultos aumentou nas últimas cinco décadas. Em 1965 nenhum dos países da OECD tinha mais de $80 \%$ de jovens adultos atingindo pelo menos o ensino médio, até 2015, todos, com exceção de seis, haviam chegado a esse limite, sinalizando um primeiro passo em direção a uma população com maior nível educacional. Em um primeiro grupo de países, que inclui Canadá, Alemanha, Letônia ou Estados Unidos, esse primeiro passo na expansão educacional foi alcançado antes de 1980. Um segundo grupo que inclui Dinamarca, a Coreia, a Noruega ou a Polónia ultrapassaram os 80\% entre 1980 e 1999. Na Austrália, França, Israel, Nova Zelândia ou Reino Unido, este ponto foi alcançado entre 1990 e 2015. Islândia, Itália, México, Portugal, Espanha e Turquia ainda não atingiram este limite (OECD, 2017). 
Muitos outros países da OECD seguiram uma abordagem de expansão simultânea do ensino médio e do ensino superior. Este é especialmente o caso, em países onde a expansão educacional começou relativamente tarde, principalmente no México, Portugal, Espanha e Turquia (OECD, 2017). Em 2015, em média, nestes países, metade de todos os jovens de 25 a 34 anos com ensino médio atingiram o ensino superior. Cinco décadas antes, em 1965, apenas $30 \%$ dos jovens adultos haviam feito isso. No mesmo ano, a proporção de jovens adultos com nível superior era maior à dos alunos do ensino médio ou pós-secundário em mais de metade dos países da OECD e ultrapassou os $60 \%$ no Canadá, Coreia, Luxemburgo, Noruega e Espanha. Em contrapartida, apenas um terço dos jovens adultos com pelo menos o ensino secundário completo obteve um diploma de nível superior na República Checa, Itália, Alemanha e República Eslovaca (OECD, 2017).

Durante as últimas décadas, a expansão educacional dos países da OCDE foi caracterizada pelo crescimento considerável do ensino superior como resposta às exigências de habilidades exigidas no século XXI e das aspirações educacionais das últimas gerações. Em contraste com a maioria desses países, a evolução do ensino superior na República Tcheca, Estônia, Letônia, Polônia e República Eslovaca pode ser caracterizada por uma parcela estável da educação superior ao longo de quarenta anos, seguido por um enorme aumento de cerca de 10 pontos percentuais ou mais entre 2005 e 2015 . Isso pode ser explicado por mudanças na política educacional durante este período: após o colapso do comunismo em 1989, o acesso ao ensino superior não era mais controlado pelo estado, mas impulsionado pela demanda, levando a uma enorme expansão dos níveis educacionais da população (KWIEK, 2013).

Diversos países adotaram políticas diferentes ao longo do tempo que moldaram seus padrões de sistema educacional. Alguns responderam ao aumento da demanda e da participação ao ampliar o período de escolaridade obrigatória e ao aumentar o estudo obrigatório. Outros expandiram seus sistemas ao proporcionar maior acesso ao ensino superior ou aplicaram as duas abordagens em diferentes estágios de seu desenvolvimento educacional. Apesar das diferenças nos sistemas educacionais e culturais dos países abordados nesta pesquisa, argumenta-se a importância em compará-los a fim de avaliar os fatores determinantes para alguns países terem se tornado fortemente competitivos e desenvolvidos e outros serem atrasados economicamente e socialmente.

Outra abordagem com foco educacional são os trabalhos que destacam a importância do investimento em educação pré-primária. Pesquisas recentes comprovam que o acesso ao préprimário tem um grande efeito no desempenho dos alunos em testes de proficiência e na habilidade comportamental não cognitiva como atenção, esforço, disciplina, e participação em 
aula (GARCES et al., 2002; GERTLER E FERNALD, 2004). Segundo Carneiro, Cunha e Heckman (2003), o retorno de investimento em educação nos Estados Unidos é muito maior para idades mais precoces. Os autores mostram que o retorno de investimento em educação é decrescente com a idade, sendo particularmente alto para educação infantil.

Os programas de incentivo ao desenvolvimento infantil na América Latina e no Caribe também apresentam resultados positivos. Beharman, Cheng e Todd (2004) relatam os efeitos do programa de pré-escola na habilidade motora, habilidade físico-social e aquisição de idiomas na Bolívia. Berlinski e Galiani (2005) mostram que o programa de construção de pré-escolas na Argentina aumentou as taxas de matrículas na pré-escola, e melhorou o desempenho cognitivo e os resultados comportamentais dos que frequentaram a pré-escola.

Para o Brasil, Curi e Menezes-Filho (2009) mostram que os alunos que frequentaram a pré-escola têm maior probabilidade de concluir o ensino fundamental do que os demais. Além disso, a influência da pré-escola é maior do que a influência da creche na conclusão do ensino médio e alunos que frequentaram a pré-escola possuem maior probabilidade de cursar uma faculdade. Portanto, a partir desses trabalhos com foco em educação infantil, pode-se observar a importância de um investimento de qualidade em educação pré-primária a fim de obter bons retornos em todas as fases educacionais.

Os economistas aceitam que o investimento em educação ou capital humano é um elemento importante no processo de desenvolvimento econômico. Estudos econométricos e outros estudos sobre o mercado de trabalho fornecem evidências muito fortes e consistentes de que trabalhadores mais educados são mais produtivos e ganham salários mais altos (PSACHAROPOULOS E PATRINOS, 2004). Tais pesquisas indicam que a educação não é apenas um dispositivo de sinalização para identificar trabalhadores mais capazes. Educação é um elemento primordial para a formação de países mais competitivos e mais ricos.

A educação especializa a mão-de-obra, aumenta a renda per capita e o poder de compra dos consumidores, além de melhorar a qualidade dos bens produzidos pelos trabalhadores especializados (SAVIOTTI et al., 2016). A mudança estrutural é importante, pois novos setores tecnológicos elevam a média salarial e a demanda por mão-de-obra qualificada, o que exige nível educacional mais alto (ANTONELLI, 2016). Sociedades mais complexas e interligadas requerem mão-de-obra especializada, o que influencia a capacidade dos agentes e, consequentemente, o desenvolvimento humano.

\subsection{A evolução da educação no Brasil}


Esta seção aborda trabalhos que discutem sobre a evolução da educação no Brasil assim como os fatores determinantes para o cenário educacional atual do país.

Segundo Andrade (1978), em meados do século XVIII, os jesuítas foram expulsos de Portugal e do Brasil, num esforço de colocar a metrópole em conformidade ao iluminismo europeu. A consequência não intencional da Reforma Pombalina no Brasil foi a destruição quase total do ensino católico, o único, praticamente, que existia na época.

As primeiras instituições de ensino superior no Brasil datam do início do século XIX a Academia militar no Rio de Janeiro, duas escolas de Direito em São Paulo e Recife, duas escolas de Medicina no Rio de Janeiro e na Bahia. Em 1838, foi fundada no Rio de Janeiro a primeira escola pública secundária, o Colégio Pedro II. O ensino primário, quando existia, ficava a cargo dos governos das províncias, de tutores particulares e padres das paróquias, exceto na capital do país, onde começaram a tomar forma os rudimentos de um sistema de ensino público.

Na década de 1890, como parte do esforço de modernização do Estado, unidades de ensino foram reunidas em grupos escolares construídos segundo os projetos arquitetônicos mais avançados da época. Os alunos eram organizados conforme a idade e proficiência e organizouse, pela primeira vez, um programa sequencial de estudos, dividido em séries anuais. Foram criadas novas escolas normais, que passaram por transformações no sentido de introduzir melhores métodos de ensino e um conteúdo moderno. Depois, surgiram tentativas de reformas semelhantes na Bahia, em Minas Gerais e no Distrito Federal (SOUZA, 1998).

No início do século XX, a maioria da população na Europa Ocidental, Inglaterra e Japão já era alfabetizada, enquanto no Brasil e em quase todos os outros países do mundo a educação formal só chegava a uma minoria ínfima. ${ }^{1}$

Em 1906, o Governo Federal aprovou uma lei para o ensino primário que reestruturou as escolas e consolidou a caligrafia vertical, considerada muito mais eficiente e adequada para se ensinar em larga escala a escrita (FARIA FILHO E GALVÃO, 1998). Entretanto, durante toda a Primeira República (1889-1930), a educação primária e média continuaram a ser de responsabilidade do governo local e estadual, e somente cerca de $25 \%$ da população, no máximo, era alfabetizada.

\footnotetext{
${ }^{1}$ Para Europa, consultar Richard L. Venezky (1991), David Vincent (2000); Para França, François Furet e Jacques Ozouf (1977). Para Japão, consulte, dentre outros, Yoshihisa Godo e Yugiro Hayami (2000). Para os Estados Unidos, Kenneth A Lockridge (1974), E. Jennifer Monaghan (1988), Edward W Stevens, Jr. (1990).
} 
Em 1924, foi fundada no Rio de Janeiro a Associação Brasileira de Educação, com participantes de vários estados e tal associação foi importante no processo de condução da educação como um assunto relevante para o país (PAIM, 1981).

Somente com a Revolução de 1930, com Getúlio Vargas no poder, deu-se início um novo período de centralização política. A educação finalmente surgiu como prioridade nacional. O novo governo criou o primeiro Ministério da Educação, além disso, duas realizações marcantes do período foram a criação do primeiro centro brasileiro de estudos e pesquisa sobre a educação, o Instituto Nacional de Estudos Pedagógicos (INEP) (XAVIER, 2000); e a reforma e atualização da antiga escola normal, que se transformou no novo Instituto de Educação do Rio de Janeiro.

Na década de 1930, o ensino primário, que deveria ser obrigatório e universal durava quatro anos, dos sete aos dez anos de idade. O ginásio, considerado como ensino secundário também durava quatro anos. Já o colegial, tinha duração de dois a três anos e foi concebido como um curso preparatório para a universidade. A primeira legislação universitária foi aprovada em 1931, entretanto, a única universidade a ser criada antes da Segunda Guerra Mundial foi a Faculdade de Ciências e Letras (SCHWARTZMAN E BROCK, 2005).

Após a $2^{\mathrm{a}}$ Guerra Mundial, o Brasil passou por um período de modernização, crescimento econômico e urbanização. Como consequência, houve uma demanda maior por educação. O Governo Federal criou uma rede de universidades federais e os governos estaduais e municipais expandiram seus sistemas de educação primária e média. Apesar desta expansão, a educação parecia menos importante nas décadas de 50 e 60 comparativamente às décadas anteriores com o Governo Vargas (SCHWARTZMAN E BROCK, 2005).

Na década de 1950, Juscelino Kubistchek conduziu o "Programa de Metas" com a finalidade de construir um país moderno, desenvolver a indústria, entre outros objetivos. Entretanto, só havia uma meta ligada à educação: o ensino técnico com menos de $4 \%$ do orçamento de investimentos (BOMENY, 2002). No mesmo período foi fundado no Rio de Janeiro o importante Centro Brasileiro de Pesquisas Educacionais (CBPE), vinculado ao antigo Inep. Desta instituição surgiram muitos estudos interessantes sobre urbanização, estratificação social e mobilidade social, mas poucos temas relacionados à educação diretamente (XAVIER, 2000).

Algumas outras reformas ocorreram nas décadas de 1960 e 1970 na educação brasileira. O ensino superior foi transformado com a introdução de inovações como o sistema de créditos, os departamentos acadêmicos e o programa de pós-graduação. Em 1971, a educação obrigatória 
passou a ser de oito anos. A expansão da pós-graduação e da pesquisa no Brasil tomou impulso na década de 1970, a partir da reforma universitária de 1968 e a reorganização do sistema de pós-graduação e pesquisa nos anos seguintes, e particularmente no governo de Ernesto Geisel, 1975-1980 (SCHWARTZMAN, 2008).

Com a Constituição de 1988, a educação foi declarada como um direito subjetivo de cada indivíduo, que todas as universidades deveriam ser autônomas, que a pesquisa, o ensino e a extensão deveriam ser inseparáveis e que todo o ensino público deveria ser proporcionado gratuitamente (SCHWARTZMAN E BROCK, 2005).

Com a gestão do presidente Fernando Henrique Cardoso, durante a década de 1990, ocorreu uma universalização do ensino básico com a inserção de métodos de avaliação de escolas e faculdades. O Inep ficou responsável pela implementação de três grandes sistemas de avaliação do ensino: o Sistema de Avaliação para o Ensino Básico (SAEB), o Exame Nacional do Ensino Médio (ENEM) e os exames nacionais para os programas de graduação (SCHWARTZMAN E BROCK, 2005).

O Brasil introduziu o Programa Bolsa Família em 2006 para combater a pobreza, oferecendo incentivos para que as famílias enviem seus filhos à escola, por meio de transferência monetária condicional e monitoramento da frequência escolar. $\mathrm{O}$ abandono escolar diminuiu entre os pobres devido a este programa. De acordo com as estatísticas nacionais, mais de um terço dos estudantes matriculados no ensino fundamental e médio receberam em 2012 o Programa Bolsa Família, com um total de 17,9 milhões de estudantes dos 50,5 milhões matriculados no ensino fundamental. O país também definiu metas educacionais por dez anos por meio do Plano Nacional de Educação entre 2014 e 2024. Este plano estabelece vinte metas e objetivos educacionais, juntamente com estratégias amplas que podem ser implementadas e definidas pelos estados e municípios (OECD, 2015).

A Emenda Constitucional no 59 do ano de 2009 aumentou a duração da escolaridade obrigatória de 9 para 14 anos e a Lei no 12796 de abril de 2013 tornou obrigatória a matrícula de crianças de 4 anos na educação na primeira infância. Entre as crianças e jovens de 5 a 14 anos, $95 \%$ estão matriculados na escola, em comparação com a média da OECD de 98\%. No Brasil, 36,1\% dos estudantes de 15 anos repetiram pelo menos um ano, cerca de três vezes a média da OECD de 12,4\%. A partir desses dados, é possível concluir que a taxa de repetência no Brasil está muito acima da média dos países em comparação, portanto, a chance de abandono escolar dos alunos repetentes é muito maior no Brasil do que nos outros países.

Outro estudo feito pela OECD sobre equidade e qualidade na educação concluiu que a repetência de série não promove melhor desempenho dos alunos, é cara e pode levar ao 
abandono escolar. No Brasil, 8\% dos jovens de 15 anos não estão na escola, em comparação com a média da Organização de $2 \%$. As principais causas para os jovens abandonarem a escola são, principalmente devido à falta de interesse, gravidez na adolescência e o custo de oportunidade da educação, particularmente nas áreas urbanas (OECD, 2015).

As perspectivas do mercado de trabalho também desempenham um papel importante na decisão de permanecer na escola. Em 2014, a taxa de desemprego entre 25 e 64 anos no Brasil era de 4,6\%, abaixo da média da OECD de 7,3\%, especialmente para aqueles com educação superior. Cerca de metade dos jovens (54\%) de 25-64 anos no país têm escolaridade abaixo do ensino médio, mas ao contrário dos países da OECD, eles tiveram uma baixa taxa de desemprego (7,4\%), comparada à média da OECD de 19,4\% em 2014. Perspectivas do mercado de trabalho são menos positivas para os jovens: a proporção de jovens de 15-29 anos sem educação, emprego ou formação era de cerca de 20,3\% em 2012, acima da média da OECD de 15,5\% em 2014. Quase metade dos desempregados são jovens, e uma parcela similar de jovens está no mercado de trabalho informal (OECD, 2015). Logo, para os jovens com menor taxa de escolaridade, as oportunidades no mercado de trabalho formal são mais escassas. Tal dado é importante como indicador de que os argumentos desta dissertação de que, quanto maior o nível educacional e de especialização da mão de obra de um país, mais complexo e desenvolvido este será são condizentes com a realidade.

Menezes-Filho (2001) mostra, por exemplo, que, apesar da melhora educacional verificada no Brasil nos últimos 20 anos, a evolução da educação foi mais lenta do que a dos demais países da América Latina.

No Brasil, o ensino superior é oferecido em instituições privadas e públicas e há altos retornos na educação. Aproximadamente $15 \%$ dos jovens entre os 25 e os 34 anos possuem ensino superior, em comparação com a média da OECD de $41 \%$ em 2014. As instituições públicas de ensino superior, em particular as instituições públicas federais, são altamente significativas. A admissão é competitiva e a maioria dos estudantes é de origem socioeconômica elevada. As universidades privadas tendem a variar mais em qualidade e compõem a maior parte das instituições de ensino superior. O sistema de avaliação da qualidade do ensino superior possui o Sistema Nacional de Avaliação da Educação Superior (SINAES, 2004), que inclui um teste para avaliar os resultados de aprendizagem no nível de graduação e o Exame Nacional de Desempenho dos Estudantes (ENADE). Indivíduos com educação superior com idades entre 25 e 64 anos ganham 2,5 vezes mais do que aqueles com ensino médio, acima da média dos 
países da OECD de cerca de 1,6. As mulheres com diploma universitário ganham cerca de $62 \%$ do que os homens ganham (em comparação com a média da OECD de 73\%) (OECD, 2015).

O investimento público do Brasil em instituições educacionais como parcela do PIB está ligeiramente acima da média dos países da OECD e quase dobrou desde 2000. O Brasil continua gastando cerca de 3,5 vezes mais em um estudante de educação superior do que em um estudante primário ou secundário, o maior diferencial entre todos os países da OECD e parceiros com dados disponíveis, apesar dos grandes aumentos nos gastos abaixo do nível superior (OECD, 2015). Logo, o investimento educacional no ensino superior é muito mais elevado do que nos ensinos primário e médio no Brasil, apesar de vários pesquisadores terem encontrados resultados de que o investimento em educação primária traz maiores retornos educacionais.

A partir dos anos 2000 o Brasil tem se esforçado pela melhoria na qualidade da educação e por novas políticas de inovação. Quanto mais avançada for a produção científica e tecnológica e quanto mais preparados estiverem os pesquisadores do país, maior será a possibilidade de se aumentar a capacidade inovadora das empresas. Da mesma forma que, quanto mais educada e qualificada for nossa população, maiores serão as chances de renovação e evolução da estrutura social brasileira (ARBIX E MIRANDA, 2015, p. 35). Logo, apesar dos investimentos em educação no Brasil nas últimas décadas, o país precisa priorizar e concentrar esforços e recursos para consolidar uma cultura de inovação em todas as dimensões da atividade econômica.

Segundo Arbix e Miranda (2015), a redução da atividade econômica desde 2010 dificultou a ampliação das políticas de inovação no Brasil. O resultado é que a distância em relação aos países mais avançados voltou a aumentar. Se a indústria não se reinventar, a ciência e a tecnologia não se desenvolverem e a inovação não se enraizar nas empresas, o Brasil corre o risco de estagnar por um longo período. Quanto mais avançada for a produção científica e quanto mais preparados estiverem os pesquisadores do país, maior será a possibilidade de se aumentar a capacidade inovadora das empresas. Da mesma forma, quanto mais educada e qualificada for a população, maiores serão as chances de renovação e evolução da estrutura social brasileira.

Para que o Brasil se diversifique é necessário que o Governo priorize uma matriz produtiva com foco na exportação de produtos com alto valor agregado, na inovação tecnológica e no desenvolvimento industrial, pois um país cuja matriz produtiva principal é o agronegócio possui limitações em relação ao preço de commodities, que não é valorizado no mercado mundial, é suscetível às crises e não exige alta escolaridade da mão de obra. Por outro lado, em um cenário com uma matriz produtiva diversificada há a criação de produtos 
inovadores, com maior valor agregado e competitividade internacional, além de trabalhadores tecnicamente mais qualificados (FERRAZ et al., 2018).

\subsection{Educação, inovação e complexidade: uma nova perspectiva de análise}

Esta seção aborda trabalhos que tratam da relação entre educação, inovação e complexidade em diversos países, além de conceitos chaves relacionadas à inovação. Discutese como alguns países, especificamente, investiram fortemente em educação, Pesquisa e Desenvolvimento (P\&D) e tecnologia a fim de se tornarem mais complexos e, consequentemente, mais competitivos.

Segundo Chen (2004) a inovação trata da introdução de uma nova combinação dos fatores essenciais de produção no sistema de produção. O capital da inovação é a competência de organizar e implementar pesquisa e desenvolvimento (P\&D), trazendo a nova tecnologia e o novo produto para atender às demandas dos clientes. Cardinal (2001) indica que o processo de inovação aborda as atividades técnicas, físicas, com base no conhecimento que são fundamentais na formação de rotinas de desenvolvimento de produtos.

O papel das universidades e de institutos públicos de pesquisa é cada vez mais reconhecido como um importante motor do crescimento econômico e do desenvolvimento industrial (SOLOW, 1957; ROMER, 1986, 1990), assim como da inovação.

Segundo Florida (2006) as universidades contribuem para o aumento da competitividade regional e da atratividade através de uma série de atividades, incluindo colaboração em pesquisa, transferência de tecnologia e licenciamento. Logo, as instituições de ensino superior são importantes impulsionadores na geração de inovação, tecnologia de ponta e mão de obra especializada. Além disso, as universidades têm assumido um papel cada vez maior no desenvolvimento de economias baseadas em ciência e tecnologia, promovendo novas capacidades nos países.

Lau e Lo (2015) e Leiponen e Helfat (2010) sugerem que a inovação e a vantagem econômica não dependem tanto dos recursos internos da organização, mas sim da sua capacidade de identificar conhecimentos externos valiosos e incorporá-la a seu próprio processo de inovação. Logo, para esses autores, a capacidade das empresas em absorver a tecnologia, inovação e conhecimento de outros países é o fator mais importante para o aumento da sua competitividade frente às concorrentes. 
A partir desta ideia de identificação e incorporação do conhecimento externo surge o conceito de spillover. Tal conceito basicamente advém do interesse teórico de desenvolver modelos que contemplem interações entre os agentes, não os vendo como tomadores de decisão isolados (ANSELIN, 1999).

Spillovers de atividades de P\&D ocorrem porque o conhecimento tecnológico não pode ser completamente apropriado por firmas e indivíduos que desenvolvem o conhecimento (VERSPAGEN E LOO, 1999). Tais efeitos de spillover também podem ocorrer por meio da proximidade tecnológica, podendo ser mensurado segundo Goto e Suzuki (1989) pela distância entre a indústria eletrônica e o resto do setor manufatureiro baseado em dados de P\&D.

O spillover do conhecimento tem sido considerado como uma fonte de inovação e crescimento econômico regional (AUDRETSCH E FELDMAN, 1996). Fallah e Ibrahim (2004) distinguiram o spillover do conhecimento e a transferência de conhecimento: o primeiro referese ao fluxo de conhecimento não intencional, enquanto o último refere-se ao intercâmbio de conhecimento intencional.

Pesquisadores como Castellacci e Natera (2013) argumentam que a capacidade de absorção do conhecimento está diretamente ligada ao nível geral de desenvolvimento econômico e social de uma região, geralmente expresso como o crescimento do Produto Interno Bruto (PIB) per capita. Isso porque o crescimento econômico pode sustentar o processo de capacitação e acumulação tecnológica, conseguindo assim uma maior capacidade de absorção.

Abramovitz (1994) defende que a capacidade de absorção do conhecimento pode se referir a capacidades relacionadas à disponibilidade de recursos, capacidade tecnológica, fator de suprimentos e escala de mercado, além da capacidade sócio institucional, por exemplo, educação. Portanto, um forte investimento dos países em acumulação tecnológica e educação são essenciais para aumentar a capacidade de absorção do conhecimento e, consequentemente aumentar a competitividade dos países frente à concorrência.

Jasimuddin (2007) e Prévot e Spencer (2006) defendem que os dois mecanismos centrais de transferência de conhecimento são a replicação e a adaptação. A replicação referese à medida que os destinatários do conhecimento transferido utilizam o mesmo sem alteração em suas operações. Com a adaptação, o destinatário modifica o conhecimento transferido antes de usá-lo. A adaptação permite que as unidades receptoras se concentrem em conhecimentos potencialmente valiosos e modifiquem ou combinem práticas de uma unidade de origem. Portanto, no mecanismo de adaptação as pessoas, empresas ou países desenvolvem e melhoram suas capacidades, por exemplo, através do desenvolvimento de uma tecnologia melhorada ou investimento em P\&D. 
Embora os spillovers do conhecimento sejam importantes para a inovação, outro fluxo de pesquisas enfatiza a importância da $\mathrm{P} \& \mathrm{D}$ nas empresas a fim de aumentar a capacidade de absorver e utilizar o conhecimento gerado em outros lugares (COHEN, LEVINTHAL, 1989). Esta literatura sugere a existência de uma relação complementar entre a própria $P \& D$ da empresa e sua capacidade para acessar os spillovers do conhecimento (GUELLEC E VAN POTTELSBERGHE DE LA POTTERIE, 2004).

Ao investir em P\&D, uma empresa pode melhorar sua conscientização e compreensão do conhecimento externo útil disponível para adoção, aumentando assim sua capacidade de absorção (COHEN E LEVINTHAL, 1989). Assim, as empresas que obtiveram maiores níveis de capacidade de absorção tendem a estar mais conscientes da presença de spillovers do conhecimento (ESCRIBANO et al., 2009).

A crescente complexidade dos processos de inovação, bem como um alto grau de incerteza tecnológica desempenha o papel mais importante. Toda vez que uma empresa introduz com sucesso uma inovação, o número de campos de conhecimento deve crescer. Além disso, as redes de $\mathrm{P} \& \mathrm{D}$ dependem de uma série de tecnologias essenciais ou de atores centrais que desempenham um papel crucial no estabelecimento das redes (SAVIOTTI, 1996, pp. 36$37)$.

Segundo Saviotti e Pyka (2004, p. 5), P\&D é o exemplo mais comum, embora não seja o único, das atividades de pesquisa e inovação que ocorrem nas empresas. Para Moralles e Rebelatto (2016), P\&D é considerado um insumo não tradicional, que define grande parte da eficiência e da competitividade das empresas, principalmente nos países em desenvolvimento, onde a indústria de máquinas e equipamentos agrícolas é geralmente o núcleo do setor de bens de capital, servindo posteriormente de base para o desenvolvimento de outras áreas.

As atividades de pesquisa fornecem o conhecimento necessário para a criação das inovações. Os novos setores e a melhora no produto compensam a diminuição da capacidade dos setores estabelecidos, gerando novos postos de trabalho de mão-de-obra especializada. Portanto, atividades de pesquisa e desenvolvimento, inovação e educação para o desenvolvimento de mão de obra qualificada são fatores relacionados e essenciais para a formação de uma nação mais complexa (SAVIOTTI E PIKA, 2004).

De acordo com Hidalgo e Hausmann (2009), apenas capital e trabalho não são suficientes para produzir produtos. Países devem ter capacidades, assim como uma infraestrutura específica, mão de obra qualificada, direitos de propriedade e regulamentos. 
Países produtores de bens de alta tecnologia necessitam de mais conhecimento avançado do que países produtores de commodities.

Hausmann et al. (2014) argumentam que economias complexas são aquelas produtoras de conhecimento por meio de uma rede de pessoas, criando uma ampla variedade de produtos intensivos em conhecimento. Por outro lado, as economias de baixa complexidade são aquelas com uma base estreita de conhecimento produtivo e produzem uma variedade menor de bens, que exigem menos conhecimento e menos integração de pessoas.

Investir na educação da população, em ciência e tecnologia é o que torna uma nação mais rica. Finlândia, Coréia do Sul e Estados Unidos são exemplos de países que priorizaram políticas de P\&D em momentos de crise (ARBIX E MIRANDA, 2015).

Na primeira metade dos anos 1990, a Finlândia mergulhou em uma profunda recessão. A produção encolheu $10 \%$ e o desemprego quadruplicou, atingindo mais de $15 \%$ da força de trabalho (OECD, 2009). Para superar as dificuldades da economia, o governo combinou medidas tradicionais como aumento de impostos e corte de gastos com o incremento do investimento em pesquisa e desenvolvimento (P\&D), assim como em educação e infraestrutura. O resultado foi a duplicação do número de ingressantes no ensino superior e a multiplicação por quatro do número de novos alunos nas escolas politécnicas.

A experiência coreana também demonstra como uma boa gestão nos períodos adversos pode acelerar ajustes estruturais (OECD, 2009). A crise que atingiu a Coreia do Sul no final dos anos 1990 causou queda no emprego de profissionais qualificados e nos investimentos privados em P\&D. Como ocorreu na Finlândia, a resposta do governo foi no sentido de investir em pesquisa, tecnologia e educação. Essas medidas contribuíram para um aumento exponencial das startups e para dobrar sua participação das mesmas nos gastos privados em P\&D, de $12 \%$, em 1997, para 24\%, em 2006. Além disso, segundo Lee (2016), no início dos anos 60, a Coréia deslocou seu foco de política econômica de substituição de importações para orientação de exportação a fim de apoiar a industrialização e o crescimento econômico. As políticas orientadas para a exportação, projetadas para fornecer incentivos às empresas exportadoras com base em seu desempenho, foram eficazes em impulsionar o ritmo da mudança na vantagem comparativa. Os exportadores conseguiram aumentar sua vantagem comparativa em manufatura intensiva de mão-de-obra e depois passar para indústrias mais intensivas em capital e intensivas em tecnologia, incluindo eletrônica, maquinaria, automóveis, navios, produtos químicos e produtos de tecnologia da informação e comunicação. Ou seja, a Coreia se tornou um país mais complexo com forte investimento em capital humano e tecnologia. 
Nos Estados Unidos, após a crise financeira de 2007-8, ocorreu uma preocupação semelhante em implementar políticas de ciência e tecnologia como alavanca para a recuperação econômica. O American Recovery and Reinvestment Act (White House, 2010) estabeleceu diretrizes para o crescimento de longo prazo e alocou cerca de US\$ 700 bilhões para serem investidos na economia. Parte desse montante, cerca de US\$ 100 bilhões, foi destinada para programas de fomento à inovação. Essa estratégia contribuiu decisivamente para o aumento observado nos investimentos em P\&D, de US\$ 59 bilhões para US\$ 68 bilhões, entre 2008 e 2014 (OECD, 2014, p. 444).

Os dados da OCDE (2014) e do Eurostat (2014) mostram que, em meados da década de 2000, os investimentos empresariais como proporção do PIB cresceram na China a uma taxa de $23 \%$ e nos Estados Unidos cresceram a uma taxa de $12 \%$. A economia da China também cresceu rapidamente nos últimos 35 anos, quando passou de uma economia socialista controlada para uma economia voltada para o mercado. Durante esse período, a China mostrou um forte crescimento da produção, que registrou uma média de mais de 9,5\% ao ano, e rapidamente reduziu sua diferença de renda per capita com a Coréia, o Japão e os EUA (OECD, 2014).

Embora a China tenha alcançado rapidamente as economias avançadas, ainda existe uma lacuna entre o desenvolvimento da China e das economias avançadas. O nível médio de renda per capita da China em relação aos EUA em 2010-2014 é menor que o da Coréia em 1990 e o do Japão em 1970. Além disso, também existem atrasos no capital humano e na qualidade das instituições entre a China e as economias avançadas, indicando que a China poderia estimular crescimento através do investimento educacional e da reforma institucional. $\mathrm{O}$ governo tem realizado reformas estruturais visando a flexibilidade do mercado de trabalho e o desenvolvimento do capital humano, a privatização de empresas públicas e a liberalização do setor financeiro. $\mathrm{O}$ aumento do investimento em $\mathrm{P} \& \mathrm{D}$ e sua alocação mais eficiente também poderiam estimular o crescimento da produtividade (LEE, 2016).

O crescimento do investimento empresarial em P\&D como proporção do PIB no Brasil cresceu a uma taxa menor, cerca de 9\% (DE NEGRI, 2015). Embora essa taxa fique próxima a de alguns países europeus, a escala e a qualidade de investimento em P\&D empresarial desses países são significativamente maiores do que no Brasil. Entre 2000 e 2013, os dispêndios em P\&D no Brasil tiveram um crescimento de $84 \%$. Este crescimento foi mais intenso nos gastos do governo federal (133\%) e menor nos do setor empresarial (61\%) e dos governos estaduais (60\%). Em termos relativos, considerando-se os dispêndios em P\&D em relação ao PIB, foi 
observado um crescimento real de $17 \%$ no período, passando de 1,04\% do PIB em 2000 para 1,24\% em 2013 (MCTI, 2015). Para um país das dimensões do Brasil, seria necessário que os investimentos em $\mathrm{P} \& \mathrm{D}$ atingissem no mínimo $2 \%$ como proporção do PIB no final desta década, o que dificilmente ocorrerá (ARBIX E MIRANDA, 2015).

No que tange à produção científica nacional, na última década o crescimento foi extremamente significativo. Em números absolutos, entre 2000 e 2014 o número de artigos de pesquisadores brasileiros publicados em periódicos indexados internacionalmente quadruplicou ao passar de 13.943 para 59.736 artigos. Em número de citações, porém, o país ainda precisa avançar, pois o impacto da produção tem evoluído de forma menos proeminente. O crescimento é de $63 \%$ no período de 2000 a 2014 e muito inferior ao registrado na produção científica. O depósito feito por residentes no país teve desempenho ainda pior, com crescimento de apenas 24\%, muito inferior ao crescimento da produção científica (328\%) (MCTI, 2015).

Os investimentos em inovação são responsáveis pelas mudanças estruturais na economia, o que pode alterar a estrutura produtiva de um país, tornando-o mais complexo. A diversificação da estrutura produtiva exige mudanças técnicas e sociais, além do desenvolvimento de novas habilidades úteis para a empresa e para a sociedade (KRUSS et al., 2015). Uma economia voltada para a exportação de produtos tecnológicos, ou seja, mais complexos, para P\&D e inovação tende a crescer e se desenvolver socialmente. 


\section{MÉTODO}

No presente capítulo são apresentados aspectos metodológicos e informações sobre as variáveis utilizadas neste trabalho. Este estudo agrupa-se na categoria de desenho de corte transversal retrospectivo, visto que não há intervenção do pesquisador, caracterizando-se, portanto, como pesquisa descritiva. Os próximos tópicos discorrem sobre os procedimentos metodológicos nas diferentes fases para o desenvolvimento desta pesquisa.

\subsection{Fonte de Dados e Variáveis}

Para a realização do presente trabalho foram coletados dados em fontes específicas de complexidade econômica, indicadores econômicos e de educação para diversos países. Os anos analisados nesta pesquisa foram entre 2007 e 2016. O banco de dados utilizado é composto 67 países. Todas as variáveis, com exceção do Índice de Complexidade Econômica, qualidade da educação e qualidade em matemática e ciências foram coletadas no site World Bank (2018). A variável de Complexidade Econômica foi obtida no Atlas de Complexidade Econômica (2018) e os indicadores de educação foram coletados do Índice de Competitividade Global. Esse índice analisa a competitividade dos países em 12 pilares: instituições, infraestrutura, ambiente macroeconômico, saúde e educação primária, ensino superior e treinamento, eficiência do mercado de bens, eficiência do mercado de trabalho, desenvolvimento do mercado financeiro, prontidão tecnológica, tamanho do mercado, sofisticação empresarial e inovação. Utiliza-se neste trabalho dois indicadores deste índice, a saber: qualidade da educação e qualidade em matemática e ciências (World Economic Forum, 2017).

Quadro 1 - Base de dados coletada e analisada no trabalho

\begin{tabular}{|c|c|c|c|c|}
\hline Variável & $\begin{array}{c}\text { Fonte } \\
\text { The Atlas of Economic } \\
\text { Complexity }\end{array}$ & $\begin{array}{c}\text { Países } \\
\text { disponíveis } \\
\text { Banco Mundial }\end{array}$ & $\begin{array}{c}\text { Anos } \\
\text { disponíveis } \\
2001-2017\end{array}$ & $\begin{array}{c}\text { Referências } \\
\text { Hidalgo e Hausmann } \\
(2009)\end{array}$ \\
Pespotis (2005) \\
PIB per capita & Banco Mundial & 116 & $2001-2017$ & Despotis (2005) \\
Formação bruta de capital fixo & Banco Mundial & 108 & $2001-2017$ & Proposta dissertação \\
Exportação de alta tecnologia & Banco Mundial & 94 & $2001-2015$ & Proposta dissertação \\
Participação força de trabalho & Banco Mundial & 118 & $2001-2015$ & Proposta dissertação \\
Exportação Manufatura & Banco Mundial & 86 & $2001-2015$ & Proposta dissertação \\
Qualidade da educação & Índice de Competitividade & 150 & $2007-2016$ & Proposta dissertação \\
Qualidade em Matemática e Ciências & Índice de Competitividade & 150 & $2007-2016$ & Proposta dissertação \\
\hline
\end{tabular}

Fonte: Elaboração própria da autora. 
Justifica-se a seleção dessas variáveis com embasamento em estudos anteriores sobre complexidade econômica e educação (SAVIOTTI E PYKA, 2004; DESPOTIS, 2005; BRETON, 2013; HIDALGO et al., 2007; HIDALGO E HAUSMANN, 2009; HAUSMANN et al., 2014; HARTMANN et al., 2014). O presente trabalho não utilizou dados sobre patentes e gastos em P\&D, pois não havia dados suficientes para os países da amostra. A fim de compensar tal deficiência foram utilizadas outras variáveis como exportação de alta tecnologia, exportação de produtos manufaturados e formação bruta de capital fixo.

\subsection{Análise Envoltória de Dados - DEA}

A Análise Envoltória de Dados - (DEA) é um método de pesquisa operacional desenvolvido por Charnes, Cooper e Rhodes (1978) que através da construção empírica de uma fronteira linear por pares, permite calcular a eficiência de um conjunto de unidades, designadas como unidades tomadoras de decisão (DMUs) (MARIANO E REBELATTO, 2014). Os principais atributos da DEA são sua versatilidade e sua capacidade de ser adaptada a muitas situações diferentes.

De acordo com Cooper et al. (2007), o DEA é um procedimento matemático baseado em programação linear, que pode determinar o conjunto de pesos que maximizam a eficiência de uma Unidade Tomadora de Decisão (DMU), permitindo incorporar múltiplas entradas e saídas em um único valor, sem a necessidade de convertê-los em uma unidade comum de medida.

Existem diferentes modelos que podem ser usados para implementar DEA que diferem de acordo com os pressupostos que adotam, a saber: a) o tipo de retornos de escala; b) a orientação; e c) a forma como os inputs e outputs são combinados. Segundo Mariano e Rebelatto (2014), o tipo de retornos de escala designa os dois principais modelos DEA: CRS (Retornos Constantes à Escala) e o VRS ou BCC (Retornos Variáveis de Escala). A hipótese do modelo CRS considera que os produtos variam proporcionalmente aos insumos em todas as regiões da fronteira (CHARNES et al., 1978). A hipótese da VRS, por outro lado, considera que a variação das saídas não é necessariamente proporcional às entradas.

A orientação pode ser o tipo radial, conforme encontrado nos modelos CCR e BCC, ou não radiais, encontrados nos modelos aditivo e multiplicativo. Os modelos radiais se concentram em minimizar os inputs ou maximizar os outputs separadamente, dado que (a) os modelos orientados aos inputs buscam determinar, dado o nível de output atual, em que medida 
os inputs podem ser reduzidos; e (b) os modelos orientados aos outputs procuram determinar, dado o nível atual de inputs, em que medida os outputs podem ser aumentados (COOPER et al, 2000). A orientação não radial simultaneamente procura reduzir os inputs e aumentar os outputs.

O modelo aditivo de Charnes et al. (1978) foi o primeiro modelo a ser desenvolvido, que pode funcionar com retornos constantes, bem como com retornos variáveis à escala. Um avanço deste modelo foi o Slack-Based Measure (SBM), proposto por Tone (2001), que tem a vantagem de gerar um índice entre zero e um como resultado. Este modelo lida com variáveis de folga, isto é, com os excessos de inputs e a escassez de outputs.

Finalmente, os modelos multiplicativos, apresentados em Charnes et al. (1978) devem ser mencionados. Esses modelos não se originam de uma combinação linear de entradas e saídas, mas sim de uma combinação geométrica entre variáveis.

O Quadro 1 mostra a formulação de base dos modelos BCC e CCR nas suas duas orientações.

Quadro 2 - Principais modelos radiais DEA na forma de multiplicadores

\begin{tabular}{|c|c|c|}
\hline Modelo & Orientado ao Input & Orientado ao Output \\
\hline CCR & $\begin{array}{l}\text { MAX } \sum_{i=1}^{m} u_{i} \cdot y_{i 0} \\
\text { Sujeitoa: } \\
\sum_{j=1}^{n} v_{j} \cdot x_{j 0}=1 \\
\sum_{i=1}^{m} u_{i} \cdot y_{i k}-\sum_{j=1}^{n} v_{j} \cdot x_{j k} \leq 0, \text { parak }=1,2, \ldots, h\end{array}$ & $\begin{array}{l}\text { MIN } \sum_{j=1}^{n} v_{j} \cdot x_{j 0} \\
\text { Sujeitoa: } \\
\sum_{i=1}^{m} u_{i} \cdot y_{i 0}=1 \\
\sum_{i=1}^{m} u_{i} \cdot y_{i k}-\sum_{j=1}^{n} v_{j} \cdot x_{j k} \leq 0, \text { parak }=1,2, \ldots, h\end{array}$ \\
\hline $\mathrm{BCC}$ & $\begin{array}{l}\text { MAX } \sum_{i=1}^{m} u_{i} \cdot y_{i 0}+w \\
\text { Sujeitoa }: \\
\sum_{j=1}^{n} v_{j} \cdot x_{j 0}=1 \\
\sum_{i=1}^{m} u_{i} \cdot y_{j k}-\sum_{j=1}^{n} v_{j} \cdot x_{j k}+w \leq 0, \text { parak }=1,2, \ldots, h \\
w \text { sem restriçãode sinal }\end{array}$ & $\begin{array}{l}\text { MIN } \sum_{j=1}^{n} v_{j} \cdot x_{j 0}-w \\
\text { Sujeitoa }: \\
\sum_{i=1}^{m} u_{i} \cdot y_{i 0}=1 \\
\sum_{i=1}^{m} u_{i} \cdot y_{j k}-\sum_{j=1}^{n} v_{j} \cdot x_{j k}+w \leq 0, \text { parak }=1,2, \ldots, h \\
w \text { sem restriçãode sinal }\end{array}$ \\
\hline
\end{tabular}

Fonte: Mariano e Rebelatto (2014, p. 5)

Em que: ${ }^{x_{j k}}$ é a quantidade do input $j$ da DMU $k ;{ }^{y_{k}}$ é a quantidade do output $i$ da DMU $k ;{ }^{x_{j 0}}$ quantidade do input $j$ da DMU em análise; ${ }^{y_{i 0}}$ quantidade do output $i$ da DMU em análise; ${ }^{v_{j}}$ 
corresponde ao peso do input $j$; ${ }^{u_{i}}$ é o peso do output $i$; ${ }^{\theta}$ significa a eficiência da DMU em análise; ${ }^{\lambda}$ é a contribuição da DMU $k$ para a meta da DMU em análise; $m$ é a quantidade de outputs analisados; ${ }_{n}$ é a quantidade de inputs analisados e; ${ }_{w}$ é o tipo de retorno de escala.

Esta dissertação utiliza o modelo DEA com a finalidade de mensurar a eficiência dos países em converter complexidade econômica em indicadores educacionais.

\subsection{Modelo econométrico}

A partir dos modelos econométricos, é possível mensurar o impacto da educação sobre a complexidade econômica. Sendo assim, formula-se a hipótese de que a educação possui impacto positivo sobre a complexidade econômica (H1). A Figura 2 mostra as variáveis educacionais utilizadas para calcular o impacto da educação sobre a complexidade econômica nos países estudados.

Figura 2 - Fluxograma e hipótese do fenômeno analisado

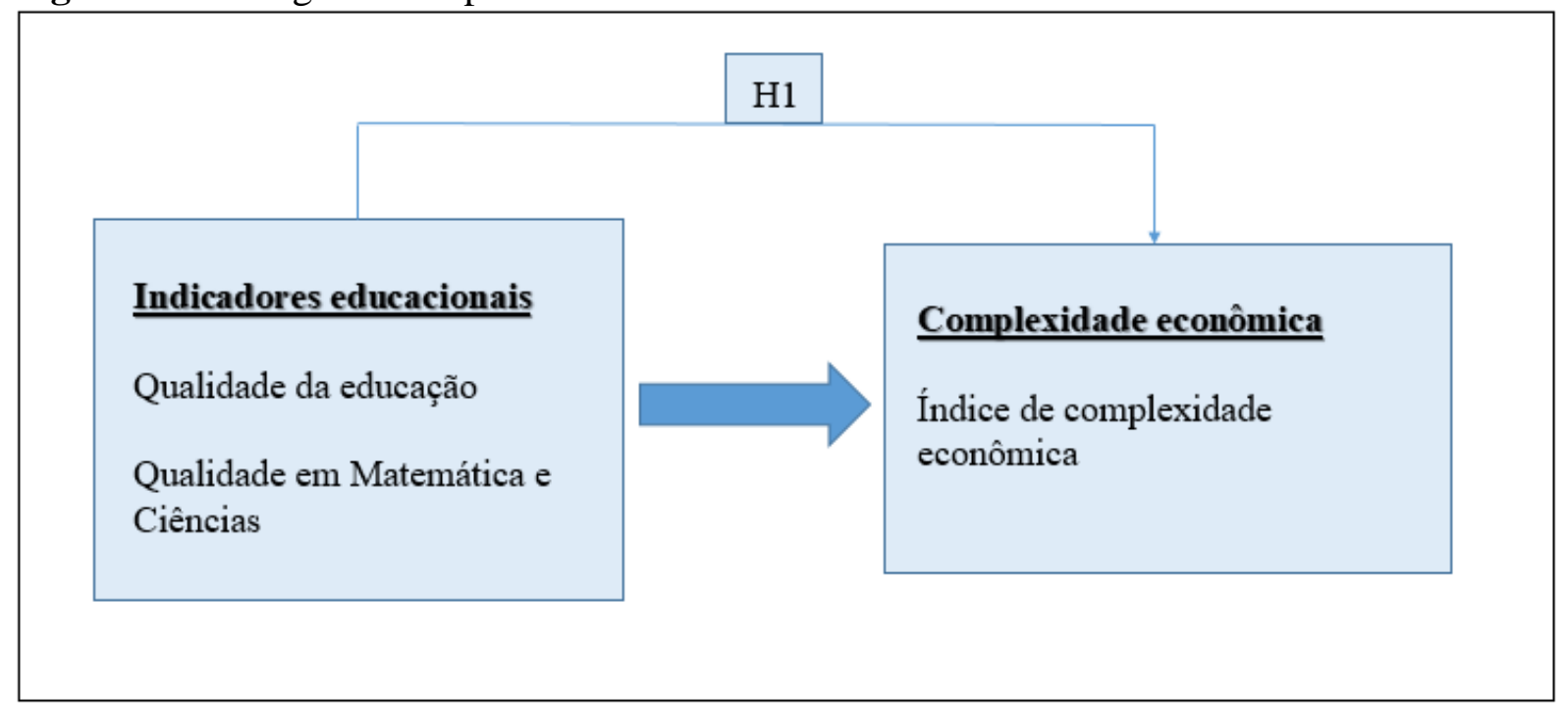

Fonte: Elaborado pela autora

Argumenta-se nesta pesquisa que a complexidade econômica está em função dos indicadores educacionais e outras variáveis macroeconômicas. A fim de verificar a hipótese proposta anteriormente, o seguinte modelo econométrico foi desenvolvido:

$Y_{i t}^{\text {complexidade }}=\beta_{0}+\beta_{1}$ txPIBpercapita ${ }_{i t}+\beta_{2}$ exportaltate $_{i t}+\beta_{3}$ expmanufatura $+^{\text {exp }}$ $\beta_{4} F B K F+\beta_{4} \sum$ educação ${ }_{i t}+\varepsilon_{i t}$ 
Em que: $Y_{i t}^{\text {complexidade }}$ representa a complexidade econômica, $t x P I B p e r c a p i t a_{i t}$ é a taxa de crescimento do PIB per capita dos países da amostra, exportaltatec $c_{i t}$ é a exportação de alta tecnologia, expmanufatura é a exportação de produtos manufaturados, $F B K F$ é a formação bruta de capital fixo e $\sum$ educação ${ }_{i t}$ representa as proxies de educação, a saber: qualidade da educação e qualidade da educação em matemática e ciências. Ressalta-se que cada proxy de educação será analisada separadamente em diferentes modelos.

A partir da fórmula geral (1) foram estimadas regressões lineares entre os inputs e outputs, nas quais variaram os indicadores educacionais utilizados. Os modelos utilizados foram construídos a fim de solucionar o problema de pesquisa.

$$
\begin{aligned}
& \text { Ln_Complexidade }_{i t}=\beta_{0}+\beta_{1} \text { txPIBpercapita }_{t-1}+\beta_{2} \text { exportaltate }_{i t}+ \\
& \beta_{3} \text { expmanufatura }_{t-2}+\beta_{4} \text { FBKF }_{t-3}+\beta_{5} \text { qualeducação }_{t-2}+\varepsilon_{i t} \\
& \text { Ln_Complexidade }_{i t}=\beta_{0}+\beta_{1} \text { txPIBpercapita }_{t-1}+\beta_{2} \text { exportaltatec }_{i t}+ \\
& \beta_{3} \text { expmanufatura }_{t-2}+\beta_{4} \text { exBKF }_{t-3}+\beta_{5} \text { qualmatciência }_{t-2}+\varepsilon_{i t}
\end{aligned}
$$

em que qualeducação $o_{i t}$ e qualmatciência $a_{i t}$ são as variáveis de indicadores educacionais.

Foram estimados os dois modelos econométricos acima a fim de avaliar quais variáveis explicam melhor o nível de complexidade econômica. Além das estimativas dos coeficientes de cada modelo, os resultados mostram a significância estatística dos parâmetros.

Optou-se pela utilização de dados em painel, também chamados de longitudinais. Um conjunto de dados de painel consiste em uma série de tempo ${ }^{1}$, para cada membro do corte transversal ${ }^{2}$, ou seja, os indivíduos presentes nos dados transversais são acompanhados ao longo do tempo. Fazer a estimação com dados em painel apresenta diversas vantagens, dentre elas: aumentar o tamanho da amostra, pois o número de observações é multiplicado pelo número de anos; controlar os efeitos causados por variáveis omitidas e controlar o efeito da heterogeneidade ${ }^{3}$ entre as firmas (WOOLDRIDGE, 2015). Cabe destacar que o painel utilizado é do tipo balanceado, ou seja, cada unidade de corte transversal tem o mesmo número de

\footnotetext{
${ }^{1}$ Um conjunto de dados de séries de tempo consiste em observações sobre uma variável ao longo do tempo.

${ }^{2}$ Um conjunto de dados de corte transversal consiste em uma amostra de uma unidade de análise, tomada em um determinado ponto no tempo.

${ }^{3}$ Heterocedasticidade é um fenômeno que ocorre quando a variância dos resíduos gerados pela regressão não é constante, com isso os estimadores não ficam viesados, mas deixam de ser eficientes.
} 
observações. Se cada unidade tivesse um número diferente de observações, teríamos um painel desbalanceado.

$\mathrm{Na}$ literatura de painel de dados também temos os termos painel curto e painel longo. Em um painel curto, o número de sujeitos de corte transversal, $\mathrm{N}$, é maior que o número de períodos de tempo, T. Em um painel longo, T é maior que N (GUJARATI E PORTER, 2011).

Dado que no modelo proposto tem-se o problema de endogeneidade em que as variáveis independentes não são totalmente exógenas, ou seja, elas estão correlacionadas com o erro, surgiu a necessidade de estimar o modelo por GMM-sys a fim de controlar a endogeneidade do modelo.

Com o intuito de encontrar um estimador eficiente que considere o efeito fixo e o potencial de endogeneidade entre os regressores, Anderson e Hsiao (1982) propuseram um método baseado na combinação do método de primeira diferença e do uso de variáveis instrumentais. Entretanto, a proposta dos autores consistiu em utilizar valores defasados e em diferença da variável dependente como instrumento para a variável dependente defasada, o que não representa o modelo proposto neste trabalho.

No caso desta pesquisa, estima-se o modelo pelo método GMM a fim de criar instrumentos para as variáveis explicativas tratadas como endógenas ou fracamente exógenas. Segundo Arellano e Bond (1991), esses casos também são contemplados pelo método GMM. No caso da endogeneidade, $X_{i t}$ é correlacionado $\operatorname{com} \varepsilon_{i t}$, mas não é correlacionado com momentos futuros $\varepsilon_{i, t+1}$. As variáveis explicativas com comportamento endógeno são tratadas de maneira parecida à variável dependente defasada. O tratamento dado para as variáveis endógenas difere do tratamento das variáveis fracamente exógenas devido ao conjunto de instrumentos utilizados nas fracamente exógenas, que admite $X_{i, t-1}$ como instrumento válido para a equação em diferença no período $t$.

O estimador GMM System (GMM-sys) combina o uso de defasagens em nível com as defasagens em diferença para corrigir o problema da endogeneidade. Logo, dado que este estimador trabalha com o problema da endogeneidade e do efeito fixo, considera-se este o mais apropriado para a estimação do modelo proposto. Assume-se que as variáveis explicativas não são correlacionadas com realizações futuras do erro, mas podem ter correlação com períodos passados.

Vale notar que, se empregado o Método de Mínimos Quadrados Ordinários (MQO) os resultados mostrariam estimativas inconsistentes, pois esse método assume a exogeneidade de todas as variáveis explicativas (GUJARATI, 2006). 


\subsection{Estatísticas Descritivas}

Primeiramente, apresentam-se as estatísticas descritivas sobre a base de dados. Elas são usadas para organizar, resumir e descrever informações importantes sobre as variáveis. É possível identificar erros nos dados apenas ao observar medidas como média, desvio padrão, valores médio e máximo e número de observações e, assim, corrigir problemas que podem viesar as estimativas.

$\mathrm{Na}$ Tabela 1 estão descritas as estatísticas descritivas das variáveis de toda a amostra utilizada. Estão presentes a média, o desvio padrão, os valores máximo e mínimo e o número total de observações para todas as variáveis utilizadas nos modelos de regressão. Para a variável Exportação alta tecnologia foi utilizado o winsorized de $2 \%$ para cada lado. Este método permite retirar os outliers que podem distorcer os resultados, sem que se perca o tamanho amostral. Apenas se repete o limitante inferior e superior nos $2 \%$ de valores mais baixos e $2 \%$ nos valores mais altos, respectivamente.

Tabela 1 - Estatísticas descritivas das variáveis do modelo

\begin{tabular}{llllll}
\hline Variáveis & Observações & Média & Desvio Padrão & Mínimo & Máximo \\
Ln (Complexidade_n) & 418 & $-0,674$ & 0,403 & $-6,893$ & 0 \\
Qualidade_Mat_Ciências & 418 & 4,239 & 0,909 & 2,081 & 6,481 \\
Qualidade_Educação & 418 & 3,938 & 0,875 & 1,912 & 6,236 \\
Taxa de crescimento PIB per capita & 418 & 0,0116 & 0,11 & $-0,64$ & 0,852 \\
Exportação Alta Tecnologia & 418 & 0,0796 & 0,361 & $-0,59$ & 2,429 \\
Exportação Manufatura & 418 & 0,583 & 0,26 & 0,002 & 3,732 \\
Taxa de Crescimento FBKF & 418 & 0,075 & 0,188 & $-0,693$ & 0,894 \\
\hline
\end{tabular}

Esta tabela representa as estatísticas descritivas do modelo

\subsection{Modelo DEA proposto}

Tendo em vista o objetivo declarado, este trabalho utilizou o Modelo DEA-BCC. Optouse por um modelo que levasse em consideração os retornos de escala, tendo em vista que são analisados em diferentes países, em que as variáveis possuem escalas distintas sobre a complexidade e a educação. Além disso, a orientação do modelo será ao output, pois se deseja maximizar o indicador de complexidade econômica (output), sem diminuir os indicadores de educação (inputs).

Como inputs foram utilizadas as seguintes variáveis: qualidade da educação em matemática e ciências e qualidade da educação. Como output foi utilizado o índice de complexidade econômica. Vale notar que existiu uma restrição para a inserção de outras 
variáveis no modelo, tendo em vista a dificuldade em encontrar séries históricas para esta análise.

O modelo assumirá que a fronteira linear por partes representa a combinação entre educação (eixo y) e complexidade (eixo x) para a produção de uma mesma quantidade de outputs sociais. O resultado corresponderá à eficiência global do processo produtivo.

Ressalta-se ainda que, a partir dos resultados dos indicadores sociais a partir do DEA, será possível verificar onde estão as melhores práticas ao redor do mundo. Sendo assim, os benchmarks poderão ser analisados, demonstrando quais tipos de ações podem ser tomadas para a elevação da eficiência dos países que não se encontram na fronteira de melhores práticas.

Além disso, optou-se para proceder com uma segunda análise a partir do DEA, utilizando a média da eficiência para todos os anos analisados. A análise temporal tem sido aplicada para levar em consideração o fator tempo (DE CASTRO CAMIOTO et al., 2014).

Por fim, dadas a sofisticação das técnicas e características do modelo proposto, o presente trabalho utilizou os softwares MATLAB e Stata para a resolução dos modelos. 


\section{RESULTADOS}

Este capítulo apresenta os resultados para os 67 países analisados nesta pesquisa. Argumenta-se ainda que os resultados são apresentados a partir do Método Generalizado dos Momentos para explicar a relação entre complexidade econômica e educação, dado que o método permite comprovar a forte correlação entre essas variáveis. Este capítulo está dividido em dois tópicos. No primeiro são apresentados os resultados econométricos para os 67 países da amostra entre os anos de 2007 a 2016. O segundo tópico apresenta a análise da eficiência para o mesmo grupo de países e anos.

\subsection{Econometria: resultados preliminares}

Nesta etapa da pesquisa optou-se por utilizar proxies de indicadores educacionais, a saber: qualidade da educação (QE) e qualidade em matemática e ciências (QMC), assim como as variáveis de exportação de alta tecnologia (EAT), índice de complexidade econômica (COM) e exportação de produtos manufaturados (LEM). Além disso, foram utilizadas variáveis de controle como, por exemplo, o PIB per capita (LPC).

A Tabela 2 apresenta o resultado da matriz de correlação entre inputs e outputs utilizados nesta pesquisa.

Os resultados da matriz de correlação mostram que as variáveis qualidade da educação (QE) e qualidade da educação em matemática e ciências (QMC) tem correlação positiva e significância estatística com o índice de complexidade econômica para ambas e mostra que países com melhores indicadores educacionais tendem a ser mais complexos.

A taxa de crescimento do PIB per capita (LPC) apresentou uma pequena correlação negativa com o índice de complexidade $(-0,086)$. A correlação entre a exportação de produtos manufaturados (LEM) e o índice de complexidade (COM) foi estatisticamente significativa e positiva $(0,39)$, o que mostra que em países exportadores de produtos com alto valor agregado, o nível de complexidade econômica tende a ser mais alto.

A variável exportação de alta tecnologia (EAT) apresentou correlação positiva e significativa com a complexidade econômica $(0,207)$, o que evidencia que quanto maior o nível de exportação de produtos com alto valor agregado, mais complexo este país tende a ser. 
A variável taxa de crescimento da formação bruta de capital fixo (TCFBKF) mostrou correlação negativa com a complexidade econômica $(-0,138)$, demonstrando que essa variável não está relacionada diretamente com o nível de complexidade de um país ou acredita-se que o investimento neste tipo de transação não esteja sendo reinvestido em complexidade econômica, mas esteja mais correlacionado ao aumento da riqueza de um país e no aumento da capacidade produtiva através de investimentos em ativos fixos. 
Tabela 2 - Matriz de Correlação entre os inputs e outputs

\begin{tabular}{|c|c|c|c|c|c|c|c|}
\hline Variáveis & $\mathrm{COM}$ & $\mathrm{QE}$ & TCPPC & EAT & EM & TCFBKF & QMC \\
\hline Ln (Complexidade_n) & 1 & & & & & & \\
\hline Qualidade_Educação & $0.439 * * *$ & 1 & & & & & \\
\hline Exportação Alta Tecnologia & $0.207 * * *$ & $-0,004$ & $0.101 * * *$ & 1 & & & \\
\hline Taxa de Crescimento FBKF & $-0.138 * * *$ & $-0.094 * *$ & $0.093 * * *$ & $0.091^{* *}$ & $-0.126^{* * *}$ & 1 & \\
\hline Qualidade Mat_Ciências & $0.512 * * *$ & - & $-0.122 * * *$ & $-0,016$ & $0.359 * * *$ & $-0.103 * *$ & 1 \\
\hline
\end{tabular}

Esta tabela representa a matriz de correlação entre as variáveis do modelo. Coeficientes estatisticamente significantes: $(* * *)$ nível de $1 \% ;(* *)$ nível de $5 \% ;(*)$ nível de $10 \%$ 
A Tabela 3 apresenta os resultados das estimativas econométricas dos dois modelos analisados pelo método GMM. Em relação ao primeiro modelo (1) encontrou-se que a variável qualidade da educação em matemática e ciências foi estatisticamente significativa e positiva ao nível de 5\%. Neste modelo, a variável taxa de crescimento PIB per capita foi estatisticamente significante ao nível de $10 \%$ e teve o sinal esperado, positivo. A variável taxa de crescimento de exportação de alta tecnologia foi estatisticamente significativa a 5\% e positiva, assim como a variável exportação de produtos manufaturas, cujo valor foi positivo e estatisticamente significativo a 5\%. Argumenta-se que o crescimento das exportações de alta tecnologia e de produtos manufaturados esteja relacionado diretamente ao aumento da complexidade econômica. Entretanto, a variável taxa de crescimento da formação bruta de capital fixo não foi estatisticamente significativa. Argumenta-se que o aumento na formação bruta de capital fixo não afeta a complexidade econômica.

No segundo modelo (2), a proxy utilizada para educação, qualidade da educação, foi estatisticamente significativa e positiva a $5 \%$. As variáveis taxa de crescimento da exportação de alta tecnologia defasada e a exportação de produtos manufaturados foram positivas e estatisticamente significativas a 5\%, evidenciando que o aumento desses fatores influencia no aumento da complexidade econômica. Neste modelo, a taxa de crescimento do PIB per capita, também defasado em um ano, foi significativo a 10\%, o que mostra que o crescimento do PIB per capita não afeta positivamente a complexidade econômica imediatamente, mas após um ano. 
Tabela 3- Estimativas econométricas para os países da amostra

Ln_Complexidade

VARIÁVEIS

(1)

Qualidade_Mat_Ciênciast-2

Qualidade_Educação $\mathrm{t}_{\mathrm{t}-2}$

Tx Cresc PIB per capitat-1

Tx Cresc Exportação Alta Tec.

Exportação Manufatura $\mathrm{t}_{-2}$

Taxa de Crescimento $\mathrm{FBKF}_{\mathrm{t}-3}$
$0.132 * *$

(0.051)

$0.107 * *$

(0.053)

$0.141^{*}$

$0.149 *$

$(0.074)$

(0.074)

$0.082 * *$

$0.083^{* *}$

$(0.031)$

$(0.033)$

$0.248^{* *}$

$0.272 * *$

$(0.122)$

(0.118)

$-0.041$

$-0.015$

(0.037)

(0.039)

Teste de Hansen (p-valor)

0,448

0,385

0,516

0,399

Teste de Diferença - Hansen (p-valor)

418
65

418

Número de ID

Esta tabela representa as estimativas econométricas dos modelos utilizados para os países da amostra. Erro-padrão entre parênteses. Os símbolos ***, ** e * mostram a significância estatística ao nível de $1 \%, 5 \%$ e 10\%, respectivamente. 
Em resumo, as variáveis utilizadas como inputs na análise econométrica possuem impacto significamente estatístico, e em sua maioria, significância estatística com a complexidade econômica (outputs).

Cabe destacar que para os dois modelos o teste de Hansen não rejeita a hipótese nula de que os instrumentos são válidos. O teste de diferença de Hansen também não rejeita a hipótese nula de exogeneidade dos instrumentos. Assim, os instrumentos utilizados são válidos e exógenos.

\subsection{Análise da eficiência entre os anos de 2007 a 2016}

Nesta etapa da pesquisa apresenta-se o resultado do ranking de eficiência dos países em converter educação em complexidade econômica. O número de DMUs utilizadas para o cálculo da eficiência foi de 67 países.

A análise de eficiência demonstra quais países foram eficientes durante os anos 2007 a 2016. Os resultados são apresentados na Tabela 4. O país que obteve a melhor posição no ranking foi a República Eslovaca (0.9625), seguida pelo Japão (0.955). Países como Suíça e Suécia também apresentaram uma boa colocação no ranking de eficiência, $5^{\mathrm{a}}$ e $6^{\mathrm{a}}$ colocação, respectivamente. Este resultado é consistente com a hipótese inicial de que países com índice educacional mais elevado como Japão, Coreia do Sul, Suíça e Suécia são mais eficientes em transformar educação em complexidade. Por outro lado, países como a República Eslovaca obtiveram boas posições no ranking de eficiência em converter educação em complexidade econômica. 
Tabela 4 - Eficiência dos países entre 2007 a 2016

\begin{tabular}{|c|c|c|c|c|c|c|c|c|c|c|c|c|c|}
\hline Ranking & País & 2007 & 2008 & 2009 & 2010 & 2011 & 2012 & 2013 & 2014 & 2015 & 2016 & Média & DP \\
\hline 1 & República Eslovaca & 0,8915 & 0,9251 & 0,9818 & 0,8398 & 1,0000 & 1,0000 & 1,0000 & 1,0000 & 1,0000 & 0,9862 & 0,9625 & 0,0543 \\
\hline 2 & Japão & 1,0000 & 1,0000 & 1,0000 & 0,5499 & 1,0000 & 1,0000 & 1,0000 & 1,0000 & 1,0000 & 1,0000 & 0,9550 & 0,1350 \\
\hline 3 & México & 1,0000 & 1,0000 & 1,0000 & 0,5379 & 1,0000 & 1,0000 & 1,0000 & 1,0000 & 1,0000 & 1,0000 & 0,9538 & 0,1386 \\
\hline 4 & Paraguai & 1,0000 & 1,0000 & 1,0000 & 0,6371 & 1,0000 & 1,0000 & 0,5431 & 1,0000 & 1,0000 & 1,0000 & 0,9180 & 0,1653 \\
\hline 5 & Hungria & 0,9363 & 1,0000 & 0,9793 & 0,4783 & 0,9495 & 0,9349 & 0,9070 & 0,9332 & 0,9806 & 1,0000 & 0,9099 & 0,1469 \\
\hline 6 & Suíça & 0,9111 & 0,9169 & 0,9283 & 0,7131 & 0,9024 & 0,9194 & 0,9278 & 0,9208 & 0,9446 & 1,0000 & 0,9084 & 0,0700 \\
\hline 7 & Suécia & 0,9210 & 0,9209 & 0,9115 & 0,9459 & 0,8657 & 0,8808 & 0,8779 & 0,9217 & 0,9182 & 0,9168 & 0,9080 & 0,0237 \\
\hline 8 & República Tcheca & 0,8335 & 0,8248 & 0,8320 & 0,7801 & 0,9644 & 0,9988 & 0,9274 & 0,9541 & 0,9348 & 0,8840 & 0,8934 & 0,0691 \\
\hline 9 & Coréia do Sul & 0,7989 & 0,8143 & 0,9009 & 0,6790 & 0,9120 & 0,8274 & 0,9256 & 1,0000 & 1,0000 & 1,0000 & 0,8858 & 0,1002 \\
\hline 10 & Áustria & 0,8381 & 0,8545 & 0,8919 & 0,9047 & 0,9058 & 0,8973 & 0,8649 & 0,8962 & 0,9173 & 0,8851 & 0,8856 & 0,0239 \\
\hline 11 & Reino Unido & 0,9038 & 0,8931 & 0,9051 & 0,8825 & 0,8487 & 0,8305 & 0,8376 & 0,8738 & 0,8555 & 0,8783 & 0,8709 & 0,0253 \\
\hline 12 & Israel & 0,6915 & 0,8243 & 0,9962 & 0,9688 & 0,8525 & 0,9017 & 0,8357 & 0,8468 & 0,8471 & 0,8242 & 0,8589 & 0,0800 \\
\hline 13 & Itália & 0,9935 & 0,9814 & 1,0000 & 0,5218 & 0,9307 & 0,8842 & 0,8229 & 0,8272 & 0,8250 & 0,7413 & 0,8528 & 0,1376 \\
\hline 14 & Egito & 0,6453 & 0,7201 & 0,5829 & 0,6048 & 0,7647 & 1,0000 & 1,0000 & 1,0000 & 1,0000 & 1,0000 & 0,8318 & 0,1751 \\
\hline 15 & EUA & 0,8802 & 0,8725 & 0,8790 & 0,5937 & 0,8607 & 0,8403 & 0,8263 & 0,8331 & 0,8413 & 0,8670 & 0,8294 & 0,0807 \\
\hline 16 & Eslovênia & 0,8644 & 0,7943 & 0,7901 & 0,9403 & 0,8597 & 0,8237 & 0,8023 & 0,8141 & 0,8048 & 0,7872 & 0,8281 & 0,0454 \\
\hline 17 & Finlândia & 0,8558 & 0,8741 & 0,8721 & 0,8225 & 0,8348 & 0,8170 & 0,8207 & 0,7997 & 0,7796 & 0,7876 & 0,8264 & 0,0314 \\
\hline 18 & Brasil & 1,0000 & 0,8079 & 0,6831 & 0,6778 & 0,6679 & 0,8587 & 0,8307 & 0,6530 & 0,9396 & 1,0000 & 0,8119 & 0,1305 \\
\hline 19 & Espanha & 0,8052 & 0,7857 & 0,8729 & 0,9030 & 0,8959 & 0,7965 & 0,7318 & 0,7418 & 0,7346 & 0,6677 & 0,7935 & 0,0740 \\
\hline 20 & Panamá & 0,7666 & 0,7142 & 0,7433 & 1,0000 & 1,0000 & 0,9814 & 0,8416 & 0,3935 & 0,3958 & 0,9130 & 0,7750 & 0,2148 \\
\hline 21 & Croácia & 0,7747 & 0,7355 & 0,7860 & 0,8507 & 0,7695 & 0,7770 & 0,7549 & 0,7772 & 0,7531 & 0,7195 & 0,7698 & 0,0334 \\
\hline 22 & Irlanda & 0,7363 & 0,7697 & 0,7784 & 0,8832 & 0,7221 & 0,7365 & 0,7566 & 0,7398 & 0,7801 & 0,7390 & 0,7642 & 0,0439 \\
\hline 23 & Polônia & 0,7636 & 0,7778 & 0,7438 & 0,8023 & 0,7679 & 0,7461 & 0,7567 & 0,7337 & 0,7271 & 0,7132 & 0,7532 & 0,0248 \\
\hline 24 & Romênia & 0,7115 & 0,7210 & 0,7334 & 0,5497 & 0,7069 & 0,7373 & 0,7534 & 0,6804 & 0,7466 & 0,9856 & 0,7326 & 0,1010 \\
\hline 25 & França & 0,7799 & 0,7991 & 0,8035 & 0,4976 & 0,7580 & 0,7545 & 0,7459 & 0,7206 & 0,7400 & 0,6908 & 0,7290 & 0,0837 \\
\hline
\end{tabular}


Dinamarca $\quad \begin{array}{llllllllllll}0,7625 & 0,7642 & 0,7586 & 0,7403 & 0,7192 & 0,7288 & 0,7055 & 0,7214 & 0,6868 & 0,6086 & 0,7196 & 0,0441\end{array}$ $\begin{array}{llllllllllllll}\text { China } & 0,7538 & 0,6858 & 0,6947 & 0,5949 & 0,6659 & 0,6904 & 0,7328 & 0,8033 & 0,8097 & 0,7249 & 0,7156 & 0,0611\end{array}$

Tailândia $\begin{array}{llllllllllll}0,5968 & 0,6235 & 0,6812 & 0,4567 & 0,7238 & 0,7602 & 0,7697 & 0,8149 & 0,8379 & 0,8198 & 0,7084 & 0,1144\end{array}$ Bélgica

Portugal

Turquia $\begin{array}{lllllllllllll}0,7277 & 0,7350 & 0,7258 & 0,7032 & 0,6749 & 0,6719 & 0,6807 & 0,6547 & 0,6532 & 0,6405 & 0,6868 & 0,0324\end{array}$ $\begin{array}{lllllllllllll}0,7433 & 0,7407 & 0,7780 & 0,7389 & 0,7358 & 0,7071 & 0,6312 & 0,6003 & 0,6061 & 0,4951 & 0,6776 & 0,0854\end{array}$ $\begin{array}{lllllllllllll}0,6679 & 0,6601 & 0,6528 & 0,6275 & 0,6662 & 0,6716 & 0,6700 & 0,6750 & 0,6956 & 0,6509 & 0,6638 & 0,0170\end{array}$

Malásia

El Salvador $\begin{array}{llllllllllll}0,5898 & 0,5959 & 0,5813 & 1,0000 & 0,5802 & 0,6391 & 0,6492 & 0,6359 & 0,6642 & 0,6627 & 0,6598 & 0,1176\end{array}$

Holanda

Filipinas $\begin{array}{lllllllllllll}0,5129 & 0,5492 & 0,5261 & 0,6403 & 0,5678 & 0,9517 & 0,6464 & 0,5440 & 0,5694 & 0,9772 & 0,6485 & 0,1634\end{array}$ $\begin{array}{lllllllllllll}0,6858 & 0,7037 & 0,6885 & 0,4754 & 0,6245 & 0,6303 & 0,6509 & 0,6181 & 0,6314 & 0,6341 & 0,6343 & 0,0603\end{array}$

Ucrânia

Lituânia $\begin{array}{llllllllllllll}0,6327 & 0,5862 & 0,5738 & 0,7833 & 0,6433 & 0,6404 & 0,6496 & 0,6349 & 0,6121 & 0,5824 & 0,6339 & 0,0563\end{array}$ $\begin{array}{lllllllllllll}0,6518 & 0,5932 & 0,6184 & 0,9074 & 0,5539 & 0,5811 & 0,5916 & 0,5503 & 0,5261 & 0,5675 & 0,6141 & 0,1035\end{array}$ $\begin{array}{lllllllllllll}0,6148 & 0,6610 & 0,6748 & 0,4658 & 0,6055 & 0,6093 & 0,6356 & 0,6280 & 0,5901 & 0,5742 & 0,6059 & 0,0549\end{array}$ Letônia

Noruega $\begin{array}{llllllllllll}0,6134 & 0,6743 & 0,6554 & 0,5047 & 0,6090 & 0,6190 & 0,6226 & 0,5871 & 0,5768 & 0,5522 & 0,6014 & 0,0467\end{array}$ $\begin{array}{lllllllllllll}0,6296 & 0,6032 & 0,6212 & 0,3475 & 0,6160 & 0,6145 & 0,6314 & 0,6455 & 0,6267 & 0,6545 & 0,5990 & 0,0850\end{array}$ $\begin{array}{lllllllllllll}0,6368 & 0,5886 & 0,6186 & 0,9237 & 0,5413 & 0,5105 & 0,5145 & 0,5059 & 0,4977 & 0,5361 & 0,5874 & 0,1213\end{array}$

Grécia

Bulgária

Colômbia

Rússia

Estônia $\begin{array}{llllllllllllll}0,6885 & 0,6775 & 0,6536 & 0,0000 & 0,6468 & 0,6489 & 0,6068 & 0,5978 & 0,6101 & 0,6158 & 0,5746 & 0,1937\end{array}$ $\begin{array}{lllllllllllll}0,5136 & 0,5504 & 0,5667 & 0,8186 & 0,4513 & 0,5458 & 0,5372 & 0,5164 & 0,5250 & 0,6408 & 0,5666 & 0,0954\end{array}$ $\begin{array}{lllllllllllll}0,6200 & 0,5014 & 0,5378 & 1,0000 & 0,4429 & 0,4950 & 0,5402 & 0,5089 & 0,4878 & 0,5293 & 0,5663 & 0,1509\end{array}$ $\begin{array}{lllllllllllll}0,6359 & 0,6008 & 0,6087 & 0,1209 & 0,5811 & 0,6051 & 0,6208 & 0,6222 & 0,6138 & 0,5700 & 0,5579 & 0,1468\end{array}$ Uruguai

Argentina Jordânia

Tunísia

Líbano

Moldova

Jamaica

Chile

Índia $\begin{array}{lllllllllllll}0,5522 & 0,5058 & 0,5290 & 0,5477 & 0,5251 & 0,6097 & 0,5787 & 0,5047 & 0,5231 & 0,6008 & 0,5477 & 0,0357\end{array}$ $\begin{array}{lllllllllllll}0,6839 & 0,6102 & 0,5666 & 0,5718 & 0,4833 & 0,5157 & 0,4870 & 0,4312 & 0,4073 & 0,4476 & 0,5204 & 0,0825\end{array}$ $\begin{array}{lllllllllllll}0,4772 & 0,4374 & 0,4796 & 0,9366 & 0,4464 & 0,4635 & 0,4357 & 0,4649 & 0,4929 & 0,4998 & 0,5134 & 0,1426\end{array}$ $\begin{array}{lllllllllllll}0,4091 & 0,4273 & 0,3989 & 0,7026 & 0,4335 & 0,4776 & 0,5483 & 0,5341 & 0,5513 & 0,5596 & 0,5042 & 0,0890\end{array}$ $\begin{array}{lllllllllllll}0,4848 & 0,5015 & 0,5005 & 0,6570 & 0,4427 & 0,4753 & 0,4915 & 0,4767 & 0,4557 & 0,4728 & 0,4958 & 0,0565\end{array}$ $\begin{array}{lllllllllllll}0,5563 & 0,5335 & 0,5172 & 0,3667 & 0,4893 & 0,5293 & 0,5764 & 0,5180 & 0,4670 & 0,3404 & 0,4894 & 0,0741\end{array}$ $\begin{array}{llllllllllll}0,4984 & 0,5255 & 0,4707 & 1,0000 & 0,4610 & 0,4496 & 0,4318 & 0,3121 & 0,3299 & 0,3698 & 0,4849 & 0,1842\end{array}$ $\begin{array}{lllllllllllll}0,5152 & 0,4647 & 0,4789 & 0,6940 & 0,4158 & 0,4563 & 0,4595 & 0,3897 & 0,3751 & 0,3524 & 0,4602 & 0,0916\end{array}$ Nova Zelândia $\begin{array}{llllllllllllll}0,4705 & 0,4836 & 0,4537 & 0,4238 & 0,3982 & 0,4475 & 0,4370 & 0,4886 & 0,4973 & 0,4905 & 0,4591 & 0,0311\end{array}$

$\begin{array}{lllllllllllll}0,4990 & 0,4976 & 0,4615 & 0,6707 & 0,3794 & 0,4457 & 0,4455 & 0,4041 & 0,3674 & 0,3883 & 0,4559 & 0,0842\end{array}$ $\begin{array}{lllllllllllll}0,3941 & 0,4335 & 0,4125 & 0,8038 & 0,3609 & 0,4067 & 0,4319 & 0,4374 & 0,4556 & 0,3923 & 0,4529 & 0,1198\end{array}$ 


\begin{tabular}{|c|c|c|c|c|c|c|c|c|c|c|c|c|c|}
\hline 56 & Macedônia & 0,4493 & 0,4420 & 0,4354 & 0,5983 & 0,3872 & 0,4391 & 0,4325 & 0,4192 & 0,3797 & 0,4145 & 0,4397 & 0,0572 \\
\hline 57 & Albânia & 0,4081 & 0,5791 & 0,6563 & 0,6470 & 0,4685 & 0,2964 & 0,3332 & 0,3387 & 0,2764 & 0,2056 & 0,4209 & 0,1520 \\
\hline 58 & Geórgia & 0,5136 & 0,3701 & 0,4204 & 0,1693 & 0,4598 & 0,4949 & 0,4997 & 0,4264 & 0,4107 & 0,3333 & 0,4098 & 0,0971 \\
\hline 59 & Paquistão & 0,3821 & 0,3907 & 0,3435 & 1,0000 & 0,1998 & 0,2438 & 0,3015 & 0,2908 & 0,2564 & 0,2502 & 0,3659 & 0,2194 \\
\hline 60 & Marrocos & 0,4063 & 0,4178 & 0,3839 & 0,1096 & 0,2805 & 0,3306 & 0,3573 & 0,3699 & 0,3215 & 0,2685 & 0,3246 & 0,0857 \\
\hline 61 & Austrália & 0,3666 & 0,3603 & 0,3120 & 0,3316 & 0,2192 & 0,2671 & 0,2869 & 0,2428 & 0,2462 & 0,3266 & 0,2959 & 0,0487 \\
\hline 62 & Bangladesh & 0,2542 & 0,2405 & 0,2058 & 0,7468 & 0,0783 & 0,2275 & 0,2710 & 0,2437 & 0,2285 & 0,2785 & 0,2775 & 0,1653 \\
\hline 63 & Moçambique & 0,1524 & 0,1142 & 0,0690 & 0,7285 & 0,0000 & 0,1987 & 0,3482 & 0,2525 & 0,2768 & 0,0000 & 0,2140 & 0,2037 \\
\hline 64 & Gana & 0,1803 & 0,1940 & 0,1739 & 0,6797 & 0,0946 & 0,1791 & 0,1961 & 0,0824 & 0,1595 & 0,1976 & 0,2137 & 0,1601 \\
\hline 65 & Camarão & 0,0000 & 0,0000 & 0,0000 & 0,5122 & 0,2412 & 0,3117 & 0,3466 & 0,2590 & 0,2015 & 0,1932 & 0,2066 & 0,1601 \\
\hline 66 & Etiópia & 0,1831 & 0,0945 & 0,0521 & 0,8833 & 0,0162 & 0,1424 & 0,1866 & 0,0647 & 0,0698 & 0,1574 & 0,1850 & 0,2392 \\
\hline \multirow[t]{3}{*}{67} & Argélia & 0,3738 & 0,2656 & 0,1729 & 0,1758 & 0,0110 & 0,0000 & 0,0000 & 0,0000 & 0,0000 & 0,3544 & 0,1353 & 0,1461 \\
\hline & Média & 0,6387 & 0,6315 & 0,6314 & 0,6622 & 0,6072 & 0,6369 & 0,6278 & 0,6101 & 0,6125 & 0,6256 & - & - \\
\hline & Desvio-Padrão & 0,2230 & 0,2284 & 0,2447 & 0,2350 & 0,2643 & 0,2452 & 0,2209 & 0,2469 & 0,2544 & 0,2573 & - & - \\
\hline
\end{tabular}

Esta tabela representa o ranking de eficiência dos países em converter complexidade econômica em indicadores educacionais. 
Os resultados acima não coincidiram com os países que foram eficientes em Mariano (2012). Na pesquisa do autor, houve uma concentração significativa, entre os países eficientes, de ex-repúblicas soviéticas e países com passados socialistas. Cabe ressaltar que tal estudo tinha como objetivo mensurar a capacidade dos países em converter a riqueza produzida em qualidade de vida. Entretanto, neste estudo, o país que obteve a melhor posição no ranking de eficiência foi a Eslováquia, uma também ex-república soviética.

Este país sofreu um crescimento lento após a separação da Tchecoslováquia em 1993, devido à liderança autoritária e aos elevados níveis de corrupção. Entretanto, com as reformas implementadas a partir de 1998, o país começou a crescer.

O sistema de ensino superior eslovaco tem tido ao longo dos últimos anos o maior aumento no número de estudantes matriculados em um programa de mestrado quando comparado aos países da Europa Central e Oriental. Além disso, a Eslováquia tem em média 4,2\% do PIB para a educação, sendo apenas $0,93 \%$ do PIB para o sistema de ensino superior. Os percentuais mais elevados dos fundos destinados ao financiamento que apoiam diretamente os estudantes estão na Eslováquia (MANTA, SARLEA E VAIDEAN, 2015).

Apesar de ser uma economia pequena, quando comparado a outros países da União Europeia, a Eslováquia se destaca pela exportação de automóveis e eletrônicos (80\% do PIB). Além disso, sua posição geográfica, no centro da Europa Central, favoreceu a exportação e o investimento para o crescimento nos últimos anos do país. Os principais países para os quais a Eslováquia exporta são Alemanha (20,7\%), República Tcheca (11,6\%), Polônia (7,7\%), França (6,3\%), Itália e Reino Unido (6\%) (CIA, 2017). Logo, dada a posição geográfica favorável do país, os fortes parceiros comerciais e os produtos exportados com alto valor agregado fortalecem o resultado do ranking de que a Eslováquia foi o país mais eficiente, dado o nível educacional do país, em maximizar a complexidade econômica.

Mesmo com todos os fatores positivos relacionados à educação e crescimento econômico da Eslováquia, o país ainda lida com vários problemas relacionados à educação, como a falta de absorção pelo mercado de mão de obra qualificada do ensino superior, o que eleva a taxa de desemprego entre os mais qualificados no país (MANTA, SARLEA E VAIDEAN, 2015).

O país que obteve a segunda colocação no ranking de eficiência foi o Japão. Este está entre uma das maiores economias do mundo e se encontrava entre os países com maior intensidade em P\&D (3,59\% do PIB) em 2014 (WORLD BANK, 2016). 
O Japão tem uma base sólida de habilidades com um grande grupo de graduados universitários e altas pontuações em avaliações internacionais de adultos em solução de problemas de tecnologia e estudantes em ciências. Segundo dados da OECD, o país tem um desempenho superior no desenvolvimento de habilidades nos jovens. Entre os países analisados pela OCDE, o Japão teve as maiores pontuações do PISA em 2015 em matemática e ciências, enquanto foi o $6^{\circ}$ em leitura. A taxa de conclusão de ensino superior entre os 25 e os 34 anos é a terceira mais alta nos países da OCDE e os adultos com educação superior têm habilidades comparativamente altas em leitura, matemática e resolução de problemas em ambientes ricos em tecnologia (OECD, 2019). Logo, alinhado às características de ser um país referência em pessoas com habilidades educacionais fortes, por possuir forte investimento em P\&D e tecnologia avançada, fortalecem o resultado encontrado de quase eficiência do país em utilizar as proxies educacionais para transformar em complexidade econômica.

O Japão é o principal país da OCDE, quando se trata de registrar patentes. O Japão também está acima da média da OCDE no número de pesquisadores por mil empregados. No entanto, o país tem um desempenho fraco em coautoria e coinvenção internacional, classificando-se próximo aos países inferiores da OCDE (OECD, 2019).

O país que ficou na terceira posição foi o México. Segundo dados disponibilizados pela OECD (2019), o país obteve um crescimento econômico considerado moderado nos últimos anos. Além disso, fez importantes reformas no sistema educacional como o Novo Modelo Educacional, de 2017, que incluem reformas no sistema no currículo escolar que visam ao desenvolvimento de competências básicas e socioemocionais (OECD, 2019).

Outros dados importantes são que o México aumentou seu nível educacional no ensino médio e superior e é um dos países da OECD que tem uma das maiores porcentagens de estudantes que ingressam em áreas de ensino superior relacionadas à ciência (OECD, 2019).

Todos esses pontos podem justificar a boa colocação do México no ranking de eficiência em converter indicadores educacionais em complexidade econômica, pois dado o nível educacional do país durante os anos analisados, este foi mais eficiente que os demais em gerar mais complexidade econômica, ou seja, dado o input disponível, o país conseguiu ser mais complexo que os demais países da amostra.

Entretanto, o México ainda tem diversos pontos a melhorar. O país ainda se encontra entre os $20 \%$ países mais pobres da OECD nos indicadores de desenvolvimento e habilidades. O país também possui uma taxa de evasão escolar alta no ensino médio, além de possuir a menor proporção da população com ensino superior entre os países da OECD (OECD, 2019). 
O Paraguai foi o país da América Latina que se destacou no ranking de eficiência. Segundo dados divulgados pelo World Bank (2019), a economia do país cresceu em média $4,5 \%$ ao ano entre 2004 e 2017, uma taxa mais elevada que a maioria das economias da região. Além disso, houve uma redução considerável da pobreza e um aumento da classe média. Entretanto, o país tem uma economia baseada na agricultura, o que o deixa vulnerável a choques de preços de commodities, além da qualidade da educação se manter no nível de países de renda média ou baixa.

O país possui uma alta capacidade para geração de energia renovável e poderia beneficiar-se dessa vantagem comparativa na promoção de produtos-chave para se tornar mais complexos e continuar a crescer a taxas significativas (WANG E LIN, 2015).

World Bank desenvolveu uma parceria com o Paraguai através de um programa de assistência técnica e empréstimos focando em três áreas principais entre 2019 e 2023 que são elas: promover instituições confiáveis e melhorar o clima do mercado, gestão de capital e integração dentro de cadeias de valor sustentáveis e construção de capital humano (WORLD BANK, 2019).

Wang e Lin (2015) destacam a importância da transição para uma estrutura produtiva diversificada: ajuda na redução da pobreza, auxilia na criação de empregos e permite a acumulação de conhecimento. Logo, apesar do Paraguai estar se destacando na América do Sul pela forte taxa de crescimento econômico, a complexidade econômica está fortemente ligada à diversificação dos produtos exportados pelo país. Portanto, é necessário que o país diversifique sua cesta de bens produzidos através de investimento em produtos em que possua vantagem comparativa e na expansão do conhecimento através da educação.

Dos países que ficaram nas piores posições no ranking de eficiência destaca-se a Austrália. Isso, apesar de dados positivos divulgados pela OECD (2019) como o fato de que o desempenho dos estudantes australianos em leitura, matemática e ciências estar acima da média da OCDE e uma grande parcela da população possuir ensino superior. Além disso, há um número relativamente grande e diversificado de australianos ativos no mercado de trabalho. Apesar disso, continuam existindo áreas nas quais a Austrália poderia melhorar. O desempenho dos estudantes australianos está diminuindo ao longo do tempo (PISA 2015).

O banco de dados de Competências para Empregos da OCDE indica que a Austrália enfrenta escassez maior do que a média da OCDE em uma série de habilidades e conhecimentos, incluindo educação, saúde e habilidades básicas. No Skills Strategy Dashboard (2019), a Austrália está na faixa dos 40\% dos países inferiores da OCDE de alinhamento entre 
a oferta de habilidades e a demanda do mercado de trabalho. Muitos trabalhadores são superqualificados para seus trabalhos.

Esses dados podem ser considerados como evidência para a posição da Austrália no ranking de eficiência em converter indicadores educacionais em complexidade econômica. $\mathrm{O}$ país possui uma mão de obra altamente qualificada, mas talvez esteja sendo subutilizada para a criação de um país mais complexo.

Outro país que não obteve destaque no ranking de eficiência foi a China. Apesar do país ser a segunda maior economia do mundo, ainda possui diversos problemas educacionais, de distribuição de renda e pobreza absoluta (WORLD BANK, 2019).

A fim de solucionar todos esses problemas, dada magnitude da economia chinesa, o país lançou o $13^{\circ}$ Plano Quinquenal da China (2016-2020) que visa, entre outras coisas, aumentar a eficiência energética, melhorar o acesso à educação e definir uma meta de crescimento anual de 6,5\% focando na qualidade do desenvolvimento (WORLD BANK, 2019).

Um dos problemas no sistema educacional chinês é que o país tem a maior proporção de jovens entre 25 a 34 anos sem ensino médio dos países da OECD. No nível de educação superior, entre 2013 e 2016, o número de estudantes chineses que estudavam no exterior aumentou $22 \%$. Os estudantes chineses representam $45 \%$ de todos os estudantes asiáticos que estudam no exterior e 25\% de todos os estudantes internacionais (OECD, 2018). Logo, apesar do forte crescimento econômico do país nos últimos anos, a China sofre com o número de pessoas que se capacitam externamente e não retornam para o país e com o não incentivo à educação.

O último país discutido com detalhamento é o Brasil que ficou em uma posição bem distante de eficiência ou quase eficiência em converter educação em complexidade econômica. O país apresenta problemas graves desde a pequena participação de formados no ensino superior em cursos como engenharia, matemática e tecnológicos, apesar da importância dessas áreas para o desenvolvimento de uma economia complexa. Apenas $15 \%$ dos formados do ensino superior no Brasil obtêm um diploma em uma dessas áreas, uma das menores participações de todos os países da OECD (média da OECD, 23\%), mas semelhante ao de outros países latino-americanos, como a Argentina (14\%) e Colômbia (13\%) que também não foram eficientes.

Embora o Brasil tenha quase atingido o número de matrículas universais entre 5 e 6 anos, a participação de crianças abaixo desta idade ainda é inferior à da maioria dos países da OECD. Apenas $37 \%$ das crianças de 2 anos e $60 \%$ das crianças de 3 anos estão matriculadas na 
educação infantil. Em 2015, 79\% das crianças de 4 anos estavam matriculadas na escola, abaixo da média da OECD de $87 \%$ e de outros países latino-americanos, como Chile (86\%), México (89\%), Argentina (81\%) e Colômbia (81\%) (OECD, 2017). Apesar da obrigatoriedade de escolarização a partir dos 4 anos, o país ainda mantém uma porcentagem de crianças matriculadas abaixo da de diversos países latinos americanos e da OECD, não incentivando ou fiscalizando a educação na infância tão importante para o desenvolvimento das crianças.

Outro fator negativo para o Brasil é a porcentagem do PIB gasta em educação infantil. O governo brasileiro investe $0,6 \%$ do seu produto interno bruto (PIB) em educação infantil (média da OECD, 0,8\%), e as instituições públicas gastam US \$ 3800 por criança por ano. Esse gasto por estudante é menos da metade da média da OECD (US \$ 8.900), mas se encontra na média de outros países latino-americanos com dados disponíveis: abaixo do Chile e da Costa Rica, mas acima da Argentina e do México (OECD, 2017).

Um dado grave sobre o nível de escolaridade da população brasileira é que mais de $50 \%$ dos jovens de 25-64 anos no Brasil não cursaram o ensino médio, o que representa mais que o dobro da média da OECD de $22 \%$ e $17 \%$ nem sequer completaram o ensino primário (média da OECD, 2\%). No entanto, houve um progresso notável nas taxas de conclusão do país. Entre a geração mais jovem (25-34 anos), a parcela com pelo menos o ensino médio aumentou de 53\% em 2010 para 64\% em 2015 (OECD, 2017). A baixa taxa de conclusão do ensino médio do país é em parte devido à baixa entrada e, em parte, devido à falta de conclusão por parte daqueles que ingressam no ensino médio.

Muitos países da OECD utilizam programas de educação e treinamento profissional como uma forma de ajudar jovens adultos a adquirir habilidades práticas e transitar mais facilmente para o mercado de trabalho. O Brasil tem um dos programas menos desenvolvidos de todos os países da OECD, respondendo por apenas 9\% dos alunos matriculados no ensino médio. A proporção de alunos do ensino médio matriculados em programas profissionais é de pelo menos 25\% em outros países da América Latina com dados disponíveis (Chile, Colômbia, Costa Rica e México) e 46\%, em média, nos países da OECD (OECD, 2017). Ou seja, além da educação primária e do ensino médio não serem bem desenvolvidas e com alta taxa de evasão, os programas profissionalizantes que auxiliam a entrada ao mercado de trabalho também não são abrangentes no país.

A formação no ensino superior no Brasil tem aumentado, mas ainda está atrás de todos os países da OECD. Apenas 15\% dos adultos entre 25-64 anos no Brasil atingiram o ensino superior, abaixo da média da OECD de 37\%, e abaixo de todos os outros países da América Latina com dados disponíveis: Argentina (21\%), Chile (22\%), Colômbia (22\%), Costa Rica 
(23\%) e México (17\%). Além disso, a disparidade por região no país também é grande. Enquanto 35\% dos jovens de 25 a 34 anos no Distrito Federal cursam o ensino superior, o mesmo vale para apenas 7\% dos que vivem no Maranhão (proporção de cinco vezes mais). É importante levar em conta variações na população e tamanhos geográficos dos estados e regiões do país e o fato de que as disparidades regionais tendem a ser maiores em países grandes. No entanto, mesmo em outros países grandes com variações significativas no tamanho, como a Federação Russa e os Estados Unidos, a proporção entre os níveis mais altos e mais baixos de conclusão é inferior a três (OECD, 2017).

Com relação aos gastos com educação, o governo brasileiro utiliza 5,4\% do PIB do ensino primário ao superior, bem acima da média da OECD de 4,8\% e acima da Argentina $(4,9 \%)$, Chile (4,0\%), Colômbia (4,2\%) e México (4,6\%). Este nível comparativamente elevado de despesa pública é majoritariamente impulsionado por despesas mais elevadas no ensino primário ao ensino médio (4,2\% do PIB), uma vez que as despesas com ensino superior (1,2\% do PIB) estão ligeiramente abaixo da média. No entanto, o país gasta apenas cerca de US \$ 1.100 por aluno em $\mathrm{P} \& \mathrm{D}$, um dos os valores mais baixos de todos os países da OECD e quase cinco vezes menos que a média da OECD de US \$ 5.100. Como resultado, a despesa total por estudante no ensino superior no Brasil é consideravelmente abaixo da média dos países da OECD, US \$ 11.700 comparados a US \$ 16.100. Ou seja, o investimento em P\&D no país é fraco e não valorizado, o que ajuda o país a se tornar não competitivo no cenário mundial.

A seguir, o Gráfico 1 apresenta a evolução da eficiência dos países discutidos. Pode-se observar como a eficiência dos países variou durante os anos de 2007 a 2016. Brasil e Paraguai tiveram as maiores oscilações durante o período e como discutido acima, a Austrália ficou em uma das últimas posições do ranking de eficiência.

Argumenta-se que o modelo utilizado no DEA é o orientado ao output, portanto, dados os indicadores de qualidade educacionais utilizados para os países, busca-se os mais eficientes em convertê-los em complexidade econômica. Portanto, o ranking e o gráfico não mostram que a Austrália ou Japão são menos complexos que o Eslováquia ou Brasil ou que a qualidade educacional mexicana foi melhor que a da Austrália nesse período, mas evidencia que a Eslováquia foi o país mais eficiente em gerar complexidade econômica, dado o indicador educacional do país. 
Gráfico 1 - Evolução da eficiência dos países selecionados entre 2007 e 2016

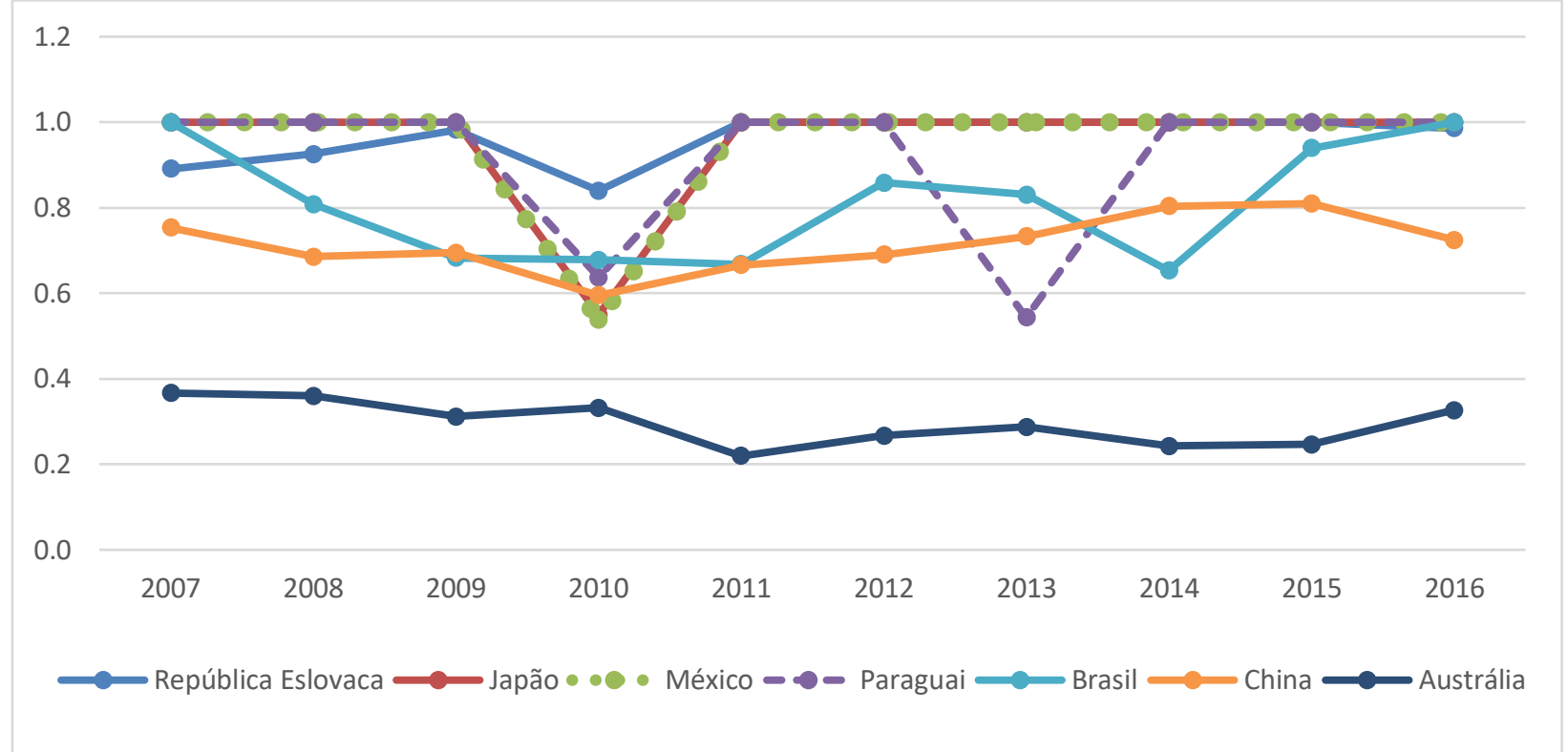

Fonte: Elaboração da autora.

Na Tabela 5 são apresentados os países que foram eficientes ou quase eficientes para os anos de 2007, 2011 e 2016. Destaca-se que o Brasil foi eficiente no ano de 2007, porém em 2011, sua posição caiu para a 29a e em 2016 teve uma forte recuperação e voltou a ser eficiente. Vale destacar que o Japão foi eficiente nos três anos considerados na tabela, o que mostra o quão eficaz o país foi em converter os indicadores educacionais em complexidade econômica. Outro país que se destacou pela eficiência nos três anos foi o México.

Tabela 5 - Eficiência dos países nos anos 2007, 2011 e 2016

\begin{tabular}{|c|c|c|c|c|c|c|}
\hline Ranking & País & 2007 & País & 2011 & País & 2016 \\
\hline 1 & Japão & 1,0000 & Paraguai & 1,0000 & Brasil & 1,0000 \\
\hline 2 & México & 1,0000 & República Eslovaca & 1,0000 & Egito & 1,0000 \\
\hline 3 & Brasil & 1,0000 & Panamá & 1,0000 & Japão & 1,0000 \\
\hline 4 & Paraguai & 1,0000 & México & 1,0000 & Suíça & 1,0000 \\
\hline 5 & Itália & 0,9935 & Japão & 1,0000 & México & 1,0000 \\
\hline 6 & Hungria & 0,9363 & República Tcheca & 0,9644 & Hungria & 1,0000 \\
\hline 7 & Suécia & 0,9210 & Hungria & 0,9495 & Paraguai & 1,0000 \\
\hline 8 & Suíça & 0,9111 & Itália & 0,9307 & Coréia do Sul & 1,0000 \\
\hline
\end{tabular}

Esta tabela representa o ranking de eficiência dos países em converter educação em complexidade econômica.

Como exposto acima, os investimentos educacionais e nível de complexidade econômica entre os países são distintos entre si. Entretanto, países que foram eficientes no ranking, considerando todos os anos da amostra, em converter indicadores educacionais em complexidade econômica não são os países com os indicadores educacionais mais elevados ou mais desenvolvidos, mas sim os países que com os indicadores educacionais utilizados, foram 
os mais eficientes para convertê-los em mais complexidade econômica. Todos estes fatores podem contribuir na justificativa de alguns países terem sido eficientes e outros não. 


\section{CONSIDERAÇÕES FINAIS}

O objetivo desta dissertação foi analisar a influência de indicadores educacionais sobre a complexidade econômica dos países entre 2007 a 2016. O conceito de educação utilizado foi o qualitativo, ou seja, qual o nível de qualidade educacional dos países, assim como a qualidade em matemática e ciências. Portanto, considerou-se que a variável qualidade e não quantidade de anos de estudo, por exemplo, possui muito mais influência no nível de complexidade econômica dos países.

Esta dissertação procurou contribuir para a literatura sobre complexidade econômica e educação, uma vez que considerou uma relação de dependência entre essas variáveis e procurou explicá-la por meio de métodos econométricos e pelo cálculo da eficiência DEA. Os resultados mostraram que a maior parte dos países eficientes ou quase eficientes em converter complexidade econômica em indicadores educacionais durante o período analisado são complexos e desenvolvidos economicamente.

Os resultados econométricos demonstraram forte correlação positiva entre as proxies utilizadas para indicadores educacionais e a complexidade econômica, ou seja, tal resultado demonstra que países com maior grau educacional tendem a ser mais complexos. As variáveis de controle taxa de crescimento do PIB per capita e taxa de crescimento da exportação de alta tecnologia foram estatisticamente significativas e positivas, evidenciando que o aumento da riqueza do país e da exportação de produtos com alto valor agregado possui um efeito positivo sobre o aumento do nível de complexidade econômica dos países. Por outro lado, a variável taxa de crescimento da formação bruta de capital fixo não foi estatisticamente significativa no modelo, o que pode evidenciar que esta variável pode não afetar diretamente o nível de complexidade econômica.

Argumenta-se que a partir do modelo econométrico GMM-sys utilizado foi possível controlar o problema da endogeneidade com a variável independente e assim obteve-se resultados não viesados e consistentes.

Este estudo avança na literatura ao apontar evidências de que a qualidade da educação possui influência positiva sobre o nível de complexidade econômica dos países. Apesar do trabalho ter focado na influência da educação sobre a complexidade econômica, argumenta-se que, países com alto nível educacional, forte investimento em P\&D e forte disseminação de conhecimento tendem a ser mais complexos economicamente e essa complexidade tende a demandar mais educação, gerando um círculo virtuoso. 
Uma limitação do trabalho é o fato da abordagem escolhida ter sido uma análise mundial, o que dificultou a disponibilidade de dados para todos os anos e para todos os países. Por isso, foram perdidos diversos países até a consolidação da base de dados final. Além disso, variáveis que seriam importantes como investimento em $\mathrm{P} \& \mathrm{D}$ e número de patentes também não puderam ser usadas por indisponibilidade de dados. Entretanto, defende-se que a pesquisa não foi prejudicada, pois outras variáveis foram usadas a fim de contornar este problema.

Outro ponto de limitação da pesquisa é que não foi considerada, no modelo, a posição geográfica dos países e a influência que tal fato pode gerar no nível de complexidade dos países, dado que tal característica é um fator importante para parcerias comerciais de exportação e transmissão de conhecimento. Salienta-se, portanto, a importância de trabalhos futuros abordarem essa variável em modelos que tratem deste tema.

Além disso, foram feitas considerações sobre os países que foram mais eficientes em converter os indicadores educacionais em complexidade econômica a fim de validar os resultados encontrados. A Eslováquia, país com a melhor posição no ranking de eficiência, possui uma posição geográfica favorável à exportação e produtos exportados com alto valor agregado, além de ter uma porcentagem do PIB considerável destinado à educação, dado o tamanho geográfico do país. Argumenta-se que tais fatores podem ter sido determinantes para a posição do país no ranking de eficiência.

Outro país também que se destacou foi o Japão. Os fatores que podem ter sido determinantes para a boa colocação do país no ranking de eficiência são o alto investimento em P\&D e tecnologia, além de possuir uma mão de obra com habilidades educacionais fortes.

México e Paraguai também tiveram boas colocações no ranking de eficiência. Argumentou-se que o fato de que o México aumentou seu nível educacional, além dos dois países terem tido crescimento econômico nos últimos anos terem sido fatores determinantes para o bom desempenho de ambos.

O Brasil não obteve destaque no ranking em converter indicadores educacionais em complexidade econômica. Vários fatores podem ter determinado a não eficiência do país, como por exemplo, o fato de que o grau de formação no ensino superior no país é baixo, a taxa de evasão dos estudantes da escola é alta e o investimento em P\&D é fraco quando comparado com outros países da OECD.

Logo, destaca-se que este trabalho procurou avaliar quais países foram mais eficientes em converter educação em complexidade econômica. Com base nos resultados encontrados, argumenta-se que os países mais eficientes não foram, necessariamente, os mais educados, com 
maior investimento em educação ou simplesmente os mais complexos, mas sim os que dado o seu nível educacional foram capazes de gerar mais complexidade econômica. 


\section{REFERÊNCIAS}

ABRAMOVITZ, M. The origins of the postwar catch-up and convergence boom. The dynamics of technology, trade and growth, Edward Elgar, Aldershot, p. 21-52, 1994.

ALTBACH, P. G.; BALÁN, J. World class worldwide: Transforming research universities in Asia and Latin America. JHU Press, 2007.

ANDERSON, T. W.; HSIAO, C. Formulation and estimation of dynamic models using panel data. Journal of econometrics, v. 18, n. 1, p. 47-82, 1982.

ANSELIN, L. Interactive techniques and exploratory spatial data analysis. Geographical Information Systems: principles, techniques, management and applications, v. 1, p. 251264, 1999.

ANTONELLI, C. Technological congruence and the economic complexity of technological change. Structural Change and Economic Dynamics, v. 38, p. 15-24, 2016.

ARBIX, G.; MIRANDA, Z. Inovação em tempos difíceis. Plural (São Paulo. Online), v. 22, n. 2, p. 18-36, 2015.

ARELLANO, M.; BOND, S. Some tests of specification for panel data: Monte Carlo evidence and an application to employment equations. The review of economic studies, v. 58, n. 2, p. 277-297, 1991.

ARROW K. (1962) The economic implications of learning by doing, Review of Economic Studies, v.29, p. 155-172.

AUDRETSCH, D. B.; FELDMAN, M. P. R\&D spillovers and the geography of innovation and production. The American economic review, v. 86, n. 3, p. 630-640, 1996.

BARRO, R. J. Determinants of economic growth: A cross-country empirical study. National Bureau of Economic Research. 1996

BARRO, R. J.; SALA-I-MARTIN, X. Technological diffusion, convergence, and growth. Journal of Economic growth, v. 2, n. 1, p. 1-26, 1997.

BEAUDRY, C.; SCHIFFAUEROVA, A. Who's right, Marshall or Jacobs? The localization versus urbanization debate. Research policy, v. 38, n. 2, p. 318-337, 2009.

BEHRMAN, J. R.; CHENG, Y.; TODD, P. E. Evaluating preschool programs when length of exposure to the program varies: A nonparametric approach. Review of economics and statistics, v. 86, n. 1, p. 108-132, 2004.

BENAVOT, A.; RIDDLE, P. The expansion of primary education, 1870-1940: Trends and Issues. Sociology of education, p. 191-210, 1988.

BENHABIB, J.; SPIEGEL, M. M. Human capital and technology diffusion. Handbook of economic growth, v. 1, p. 935-966, 2005.

BENHASSINE, N. Essays on inequality, redistribution and wealth-based politics. 2001. Massachusetts Institute of Technology

BOMENY, H. Utopias de cidade: as capitais do modernismo. O Brasil de JK, v. 2, p. 207, 2002. 
BOURGUIGNON, F.; MORRISSON, C. Inequality among world citizens: 1820-1992. American economic review, v. 92, n. 4, p. 727-744, 2002.

BOURGUIGNON, F.; VERDIER, T. Oligarchy, democracy, inequality and growth. Journal of development Economics, v. 62, n. 2, p. 285-313, 2000.

BRETON, T. R. The role of education in economic growth: theory, history and current returns. Educational Research, v. 55, n. 2, p. 121-138, 2013.

CARDINAL, L. B. Technological innovation in the pharmaceutical industry: The use of organizational control in managing research and development. Organization science, v. 12, n. 1, p. 19-36, 2001.

CARNEIRO, P.; CUNHA, F.; HECKMAN, J. J. Interpreting the evidence of family influence on child development. The Economics of Early Childhood Development: Lessons for Economic Policy, 2003.

CASTELLACCI, F.; NATERA, J. M. The dynamics of national innovation systems: A panel cointegration analysis of the coevolution between innovative capability and absorptive capacity. Research Policy, v. 42, n. 3, p. 579-594, 2013.

DE CASTRO CAMIOTO, F.; MARIANO, E. B.; DO NASCIMENTO REBELATTO, D. A. Efficiency in Brazil's industrial sectors in terms of energy and sustainable development. Environmental Science \& Policy, v. 37, p. 50-60, 2014.

CENTRAL INTELLIGENCE AGENCY. The World Factbook 2017. Central Intelligence Agency, 2017.

CHARNES, A.; COOPER, W. W.; RHODES, E. Measuring the efficiency of decision making units. European journal of operational research, v. 2, n. 6, p. 429-444, 1978.

CHEN, C. J. The effects of knowledge attribute, alliance characteristics, and absorptive capacity on knowledge transfer performance. R\&D Management, v. 34, n. 3, p. 311-321, 2004.

CIPOLLA, C. M. Literacy and Development in the West. Penguin, 1969.

COHEN, W. M.; LEVINTHAL, D. A. Innovation and learning: the two faces of R \& D. The economic journal, v. 99, n. 397, p. 569-596, 1989.

COOPER, W. Seiford. LM and Tone, K.(2000) Data Envelopment Analysis: A Comprehensive Text with Models, Applications, References and DEA-Solver Software: Boston: Kluwer Academic Publishers 2007.

COSTINOT, A. On the origins of comparative advantage. Journal of International Economics, v. 77, n. 2, p. 255-264, 2009.

CORRAR, L. J.; PAULO, E.; DIAS FILHO, J. M. Análise multivariada: para os cursos de administração, ciências contábeis e economia. São Paulo: Atlas, p. 280-323, 2007.

CURI, A. Z.; MENEZES-FILHO, N. A. A relação entre educação pré-primária, salários, escolaridade e proficiência escolar no Brasil. Estudos Econômicos (São Paulo), v. 39, n. 4, p. 811-850, 2009.

DE ANDRADE, A. A. B. A reforma pombalina dos estudos secundários no Brasil. Edição Saraiva, 1978. 
DE FARIA FILHO, L. M. Modos de ler, formas de escrever: estudos de história da leitura e da escrita no Brasil. Autêntica, 1997.

DE NEGRI, J. Avançar ou avançar na política de inovação. Indústria e desenvolvimento produtivo no Brasil. Rio de Janeiro: Elsevier, p. 359-375, 2015.

DE SOUZA, R. F. Templos de civilização: a implantação da escola primária graduada no Estado de São Paulo, 1890-1910. Unesp, 1998.

EDLER J., FIER H. and GRIMPE C. International scientist mobility and the locus of knowledge and technology transfer, Research Policy, v.40, p. 791-805, 2011. doi:10.1016/j.respol.2011.03.003

ESCRIBANO, A.; FOSFURI, A.; TRIBÓ, J. A. Managing external knowledge flows: The moderating role of absorptive capacity. Research policy, v. 38, n. 1, p. 96-105, 2009.

FALLAH, M. H.; IBRAHIM, S. Knowledge spillover and innovation in technological clusters. Proceedings, IAMOT 2004 Conference, Washington, DC, 2004. p.1-16.

FELIPE, J. et al. Product complexity and economic development. Structural Change and Economic Dynamics, v. 23, n. 1, p. 36-68, 2012.

FERRARINI, B.; SCARAMOZZINO, P. Production complexity, adaptability and economic growth. Structural Change and Economic Dynamics, v. 37, p. 52-61, 2016.

FERRAZ, D. et al. Economic Complexity and Human Development: DEA performance measurement in Asia and Latin America. Gestão \& Produção, n. forthcoming, 2018.

FLORIDA, R. The flight of the creative class: The new global competition for talent. Liberal Education, v. 92, n. 3, p. 22-29, 2006.

GALA, P. Complexidade Econômica: Uma nova perspectiva para entender a antiga questão da riqueza das nações. Rio de Janeiro: Contraponto, 2017.

GALIANI, S.; BERLINSKI, S. The effect of a large expansion of pre-primary school facilities on preschool attendance and maternal employment. 2005

GARCES, E.; THOMAS, D.; CURRIE, J. Longer-term effects of Head Start. American economic review, v. 92, n. 4, p. 999-1012, 2002.

GERTLER, P.; FERNALD, L. C. The medium term impact of Oportunidades on child development in rural areas. Unpublished manuscript, University of California at Berkeley, 2004.

GLAESER, Edward L. et al. Growth in cities. Journal of political economy, v. 100, n. 6, p. 1126-1152, 1992.

GOTO, A.; SUZUKI, K. R \& D capital, rate of return on R \& D investment and spillover of R $\&$ D in Japanese manufacturing industries. The Review of Economics and Statistics, p. 555564, 1989.

GREENE, W. H. Econometric analysis, 71e. Stern School of Business, New York University, 2012.

GROSSMAN, G. M.; HELPMAN, E. Quality ladders in the theory of growth. The Review of Economic Studies, v. 58, n. 1, p. 43-61, 1991. 
Innovation and growth in the global economy. MIT press, 1993.

GUELLEC, D.; VAN POTTELSBERGHE DE LA POTTERIE, B. From R\&D to productivity growth: Do the institutional settings and the source of funds of R\&D matter? Oxford Bulletin of Economics and Statistics, v. 66, n. 3, p. 353-378, 2004.

GUJARATI, D. N.; PORTER, D. C. Econometria Básica-5. Amgh Editora, 2011.

GUJARATI, D. N. Econometria Básica. Tradução Maria José Cyhlar Monteiro: Rio de Janeiro: Elsevier 2006.

HANUSHEK, E. A.; KIMKO, D. D. Schooling, labor-force quality, and the growth of nations. American economic review, v. 90, n. 5, p. 1184-1208, 2000.

HANUSHEK, E. A.; W ÖBMANN, L. Does educational tracking affect performance and inequality? Differences-in-differences evidence across countries. The Economic Journal, v. 116, n. 510, p. C63-C76, 2006.

HANUSHEK, E. A.; WOESSMANN, L. The role of cognitive skills in economic development. Journal of economic literature, v. 46, n. 3, p. 607-68, 2008.

HARTMANN, D. et al. Linking economic complexity, institutions and income inequality. arXiv preprint arXiv:1505.07907, 2015.

HARTMANN, D. Economic Complexity and Human Development. Abingdon: Routledge, 2014.

HAUSMANN, R. et al. The atlas of economic complexity: Mapping paths to prosperity. Mit Press, 2014.

HAUSMANN, R.; HWANG, J.; RODRIK, D. What you export matters. Journal of economic growth, v. 12, n. 1, p. 1-25, 2007.

HIDALGO, C. Why information grows. The evolution of Order, from Atoms to Economies.(Ebook) New York: Basic Books, 2015.

HIDALGO, C. A.; HAUSMANN, R. The building blocks of economic complexity. Proceedings of the national academy of sciences, v. 106, n. 26, p. 10570-10575, 2009.

HIDALGO, C. A. et al. The product space conditions the development of nations. Science, v. 317, n. 5837, p. 482-487, 2007.

HOLLAND, M.; XAVIER, C. L. Dinâmica e competitividade setorial das exportações brasileiras: uma análise de painel para o período recente. Encontro Nacional de Economia, v. 32, 2004.

HOWITT, P.; AGHION, P. Capital accumulation and innovation as complementary factors in long-run growth. Journal of Economic Growth, v. 3, n. 2, p. 111-130, 1998. ISSN 13814338. INDIRESAN, P. Prospects for world-class research universities in India. World class worldwide: Transforming research universities in Asia and Latin America, p. 95-121, 2007.

JACOBS J. (1969) The Economy of Cities. Random House, New York, NY, 1969.

JAMISON, E. A.; JAMISON, D. T.; HANUSHEK, E. A. The effects of education quality on income growth and mortality decline. Economics of Education Review, v. 26, n. 6, p. 771788, 2007. 
JASIMUDDIN, S. M. Exploring knowledge transfer mechanisms: The case of a UK-based group within a high-tech global corporation. International Journal of Information Management, v. 27, n. 4, p. 294-300, 2007.

JOHANSSON, E. The history of literacy in Sweden: In comparison with some other countries. Educational Reports Umeå 1977.

KALDOR, N. Strategic factors in economic development. 1967.

KIM, K.-S.; NAM, S. The making of a world-class university at the periphery: Seoul National University. World class worldwide: Transforming research universities in Asia and Latin America, p. 122-142, 2007.

KLIKSBERG, B. Falácias e mitos do desenvolvimento social. Cortez, 2001. ISBN 8524908238.

KREMER, M. The O-ring theory of economic development. The Quarterly Journal of Economics, v. 108, n. 3, p. 551-575, 1993.

KRUSS, G. et al. Higher education and economic development: The importance of building technological capabilities. International Journal of Educational Development, v. 43, p. 22$31,2015$.

KWIEK, M. From system expansion to system contraction: Access to higher education in Poland. Comparative Education Review, v. 57, n. 3, p. 553-576, 2013.

LALL, S. Technological capabilities and industrialization. World development, v. 20, n. 2, p. 165-186, 1992.

LAU, A. K.; LO, W. Regional innovation system, absorptive capacity and innovation performance: An empirical study. Technological Forecasting and Social Change, v. 92, p. 99-114, 2015.

LEE, J. W. Korea's Economic Growth and Catch-up: Implications for China. China \& World Economy, v. 24, n. 5, p. 71-97, 2016.

LEIPONEN, A.; HELFAT, C. E. Innovation objectives, knowledge sources, and the benefits of breadth. Strategic Management Journal, v. 31, n. 2, p. 224-236, 2010.

LEVINE, R.; RENELT, D. A sensitivity analysis of cross-country growth regressions. The American economic review, p. 942-963, 1992.

LEWIS, W. Arthur: The Theory of Economic Growth. Homewood, v. 111, p. 9, 1955.

LIU, N. C. Research universities in China: Differentiation, classification, and future world-class status. World class worldwide: Transforming research universities in Asia and Latin America, p. 54-69, 2007.

Lin JY, Wang Y. Catching up: structural transformation and diversification. In: Felipe J, editor. Development and modern industrial policy in practice. Issues and country experiences. Cheltenham UK: Edward Elgar Pub; 2015.

LOPEZ, R.; THOMAS, V.; WANG, Y. The quality of growth: Fiscal policies for better results. 2008.

LUCAS JR, R. E. On the mechanics of economic development. Journal of monetary economics, v. 22, n. 1, p. 3-42, 1988. 
1993.

Making a miracle. Econometrica: Journal of the Econometric Society, p. 251-272,

MANKIW, N. G.; ROMER, D.; WEIL, D. N. A contribution to the empirics of economic growth. The quarterly journal of economics, v. 107, n. 2, p. 407-437, 1992.

MARIANO, E. B. Crescimento econômico e desenvolvimento humano: uma análise mundial da eficiência social de Estados-nação. Universidade de São Paulo

MARIANO, E. B.; DO NASCIMENTO REBELATTO, D. A. Transformation of wealth produced into quality of life: analysis of the social efficiency of nation-states with the DEA's triple index approach. Journal of the Operational Research Society, v. 65, n. 11, p. 1664$1681,2014$.

MARSHALL A. (1890) Principles of Economics. Macmillan, London.

MENEZES-FILHO, N. A. A evolução da educação no Brasil e seu impacto no mercado de trabalho. Instituto Futuro Brasil, p. 1-43, 2001.

MORALLES, H. F.; DO NASCIMENTO REBELATTO, D. A. The effects and time lags of R\&D spillovers in Brazil. Technology in Society, v. 47, p. 148-155, 2016.

MORRISSON, C.; MURTIN, F. Education Inequalities and the Kuznets Curves 1870-2000. Working Paper, Paris School of Economics. 2008

OECD (2005), "Jamaica", in World Education Indicators 2005: Education Trends in Perspective, OECD Publishing, Paris, http://dx.doi.org/10.1787/wei-2005-11-en.

OECD Science, Technology and Industry Outlook 2014. Paris: OECD Publishing, 2014. Disponível em: <http://www.keepeek.com/ Digital-Asset-Management/ oecd/science-andtechnology/oecd-science-technology-and-industry-outlook-2014_sti_outlook-2014-

en\#page $1>$.

OECD. OECD SCIENCE, Technology and Industry Scoreboard 2015. Paris: OECD Publishing, 2015. Disponível em: www.keepeek.com/Digital-Asset-Management/oecd/ science-and-technology/oecd-science-technology-and-industry-scoreboard-2015_

sti_scoreboard-2015-en\#page1.

OECD (2015), Education Policy Outlook 2015: Making Reforms Happen, OECD Publishing, Paris, http://dx.doi.org/10.1787/9789264225442-en.

OECD (2017), Education at a Glance 2017: OECD Indicators, OECD Publishing, Paris, http://dx.doi.org/10.1787/eag-2017-en

OECD (2019), OECD Skills Strategy 2019: Skills to shape a better future, OECD Publishing, Paris, //doi.org/10.1787/9789264313835-en.

OECD (2019), OECD Economic Surveys: Mexico 2019, OECD Publishing, Paris, https://doi.org/10.1787/a536d00e-en.

OECD (2019), Education GPS: The world of education at your fingertips. Disponível em: < http://gpseducation.oecd.org/ >. Acesso em: 17 jun. 2019.

PAIM, A. A UDF e a idéia de universidade. Rio de Janeiro: Tempo Brasileiro, 1981. 
PRÉVOT, F.; SPENCER, R. Supplier competence alignment: Cases from the buyer perspective in the Brazilian market. Industrial Marketing Management, v. 35, n. 8, p. 944-960, 2006.

PSACHAROPOULOS, G.; PATRINOS*, H. A. Returns to investment in education: a further update. Education economics, v. 12, n. 2, p. 111-134, 2004.

RANIS, G.; STEWART, F.; RAMIREZ, A. Economic growth and human development. World development, v. 28, n. 2, p. 197-219, 2000.

ROMER, P. M. Growth based on increasing returns due to specialization. The American Economic Review, v. 77, n. 2, p. 56-62, 1987.

. Endogenous technological change. Journal of political Economy, v. 98, n. 5, Part 2, p. S71-S102, 1990.

ROSTOW, W. W. The stages of economic growth. The Economic History Review, v. 12, n. 1, p. 1-16, 1959.

SAVIOTTI, P. P. Technological evolution, variety and the economy. Books, 1996.

SAVIOTTI, P. P.; PYKA, A. Economic development by the creation of new sectors. Journal of evolutionary economics, v. 14, n. 1, p. 1-35, 2004.

. From necessities to imaginary worlds: Structural change, product quality and economic

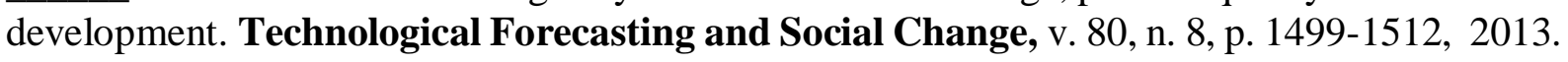

SAVIOTTI, P. P.; PYKA, A.; JUN, B. Education, structural change and economic development. Structural Change and Economic Dynamics, v. 38, p. 55-68, 2016.

SAXENIAN A. and HSU J. Y. The Silicon Valley-Hsinchu connection: technical communities and industrial upgrading. Industrial and Corporate Change, v.10, p. 893-920, 2001. doi: $10.1093 / \mathrm{icc} / 10.4 .893$

SCHWARTZMAN, S. " Pesquisa Universitária e Inovação no Brasil. Avaliação de políticas, p. 19, 2008.

SCHWARTZMAN, S.; BROCK, C. Os desafios da educação no Brasil. Os desafios da educação no Brasil. Rio de Janeiro: Nova Fronteira, p. 9-51, 2005.

SOLOW, R. M. A contribution to the theory of economic growth. The quarterly journal of economics, v. 70, n. 1, p. 65-94, 1956.

STOKEY, N. L. Learning by doing and the introduction of new goods. Journal of Political Economy, v. 96, n. 4, p. 701-717, 1988.

Human capital, product quality, and growth. The Quarterly Journal of Economics, v. 106, n. 2, p. 587-616, 1991.

TACCHELLA, A. et al. Economic complexity: conceptual grounding of a new metrics for global competitiveness. Journal of Economic Dynamics and Control, v. 37, n. 8, p. 16831691, 2013.

VERSPAGEN, B.; DE LOO, I. Technology spillovers between sectors. Technological Forecasting and Social Change, v. 60, n. 3, p. 215-235, 1999.

WANG, Z.; WEI, S.-J.; WONG, A. Does a leapfrogging growth strategy raise growth rate? Some international evidence. National Bureau of Economic Research. 2010 
XAVIER, L. N. O Brasil como laboratório: educação e ciências sociais no projeto do Centro Brasileiro de Pesquisas Educacionais CBPE/INEP/MEC (1950-1960). Centro de Documentação e Apoio à Pesquisa em História da Educação, Instituto Franciscano de Antropologia, Universidade São Francisco, 1999.

YONEZAWA, A. Making" World-class Universities". Higher Education Management and Policy, v. 15, n. 2, p. 9-23, 2003.

YOUNG, A. Learning by doing and the dynamic effects of international trade. The Quarterly Journal of Economics, v. 106, n. 2, p. 369-405, 1991.

WHITE HOUSE. The Recovery Act: Transforming the American Economy Through Innovation. 2010. Disponível em: <https://www.whitehouse.gov/sites/default/files/ uploads/Recovery_Act_Innovation.pdf>.

WOOLDRIDGE, J. M. Econometric analysis of cross section and panel data. MIT press, 2010 .

World Bank. 2019. The Challenge of a Generation : The Leap Towards a High-Income Economy : About the International Commission for Equity, Growth, and Development (English). Washington, D.C. : World Bank Group.

World Economic Forum. The Global Competitiveness Index dataset 2007-2017.

ZHU, S.; FU, X. Drivers of export upgrading. World Development, v. 51, p. 221-233, 2013. 